\title{
Analyzing Driving Forces of China's Carbon Emissions From 1997-2040 and the Potential Emission Reduction Path: Through Decomposition and Scenario Analyses
}

\section{Ce Song ( $\nabla$ ce_song@tju.edu.cn )}

Tianjin University https://orcid.org/0000-0003-4148-6185

\section{Tao Zhao}

Tianjin University

Juan Wang

Tianjin University of Finance and Economics

\section{Research Article}

Keywords: carbon emissions, decomposition model, scenario analysis, provincial analysis

Posted Date: June 2nd, 2021

DOl: https://doi.org/10.21203/rs.3.rs-560303/v1

License: (c) (1) This work is licensed under a Creative Commons Attribution 4.0 International License. Read Full License

Version of Record: A version of this preprint was published at Clean Technologies and Environmental Policy on November 26th, 2021. See the published version at https://doi.org/10.1007/s10098-021-022407. 
Analyzing driving forces of China's carbon emissions from 1997-2040 and the potential 2 emission reduction path: Through decomposition and scenario analyses

3 Ce Song*, Tao Zhao, Juan Wang

4 School of Economics \& Management, Tianjin University, Tianjin 300072, PR China

5 Corresponding author. Tel.: +8615922208350

6 Email address: ce_song@tju.edu.cn (Ce Song)

\section{Abstract}

8 To assess the evolution trend of China's carbon emissions (CEs) and related driving factors, this paper used 9 scenario analysis to predict China's CEs from 2017 to 2040 at the industrial level. Then, LMDI decomposition 10 model was applied to evaluate the driving forces of CEs changes during 1997-2040. Finally, the ST-LMDI model was used to explore the CEs reduction potential and the potential reduction path at provincial level. The results showed that (1) as the reduction of energy intensity cannot offset the growth of industrial scale, the CEs of all industries have shown an increasing trend from 1997 to 2017; (2) In the current policy scenario, China's CEs cannot reach the peak before 2040. And only in the sustainable development scenario, the CEs of the three industries will all reach the peaks before 2030. And the development of non-fossil energy will reduce CEs by more than 30\%; (3) Hebei, Shanxi, Inner Mongolia, Ningxia, and Heilongjiang are key provinces and improving energy efficiency of the secondary industry is a potential way to promote CEs reduction.

Key Words: carbon emissions, decomposition model, scenario analysis, provincial analysis

\section{Introduction}

China's economy has grown rapidly in recent decades and has become the second largest economy in the world (Jiang et al., 2018). However it also brings serious environmental problems. In 2009, China surpassed the United States to become the world's largest carbon emitter (Wang et al., 2010). In 2017, total CEs in China were 9866Mtons, accounting for $30.05 \%$ of the global total (IEA, 2018). Resources and environmental problems have brought huge potential threatens to the sustainable development of China (Liu et al., 2018). Faced with increasingly serious environmental problems, the Chinese government has issued a series of policies aimed at energy consumption transformation and industrial structure optimization in an attempt to control the fossil fuel consumption and related CEs (Deng et al., 2019). In 2016, the State Council promulgated the "13th Five-Year Plan", requiring China to decrease the carbon intensity (CI) by 18\% in 2020 compared to 2015 (NDRC, 2017). In 2017, the Chinese government promulgated the National Independent Contribution Program (INDC), promising to reduce CI by 60\% to 65\% from the 2005 level, and peaked China's CEs in 2030 (Yuan et al., 2018). In 2021, according to the 14th Five-Year Plan, China pledged to achieve carbon neutrality by 2060 (NDRC, 2021).

The implementation of a series of emission reduction policies has had a certain effect on restraining the growth of CEs of China (Ding et al., 2019; Wang et al., 2018a). From 2013 to 2017, China's CEs increased from 9492.9Mtons to 9866Mtons, with an average annual growth rate of $0.98 \%$, which was much lower than the 7.61\% during 1997-2013 (NBSC, 1998-2018b). This raised some questions: What are the characteristics of China's CEs at different stages? How will China's CEs change in the future? In different scenarios, what 
are the main drivers for the dynamics of CEs? In addition, China has a huge territory. The industrial structure and resource endowments vary greatly among provinces. There are serious inequalities in CEs among provinces. In 2017, the five provinces with the largest CEs were Shandong (806Mtons), Jiangsu (736Mtons), Hebei (726Mtons), Inner Mongolia (639Mtons) and Guangdong (542Mtons), accounting for $34.96 \%$ of the national total. On the contrary, the five provinces with the least CEs were Hainan (42Mtons), Qinghai (53Mtons), Beijing (85Mtons), Tianjin (141Mtons), and Gansu (151Mtons), accounting for only $4.78 \%$ of the national total. Considering that CEs reduction targets are closely related to each province, evaluating the driving factors of provincial CEs changes and identifying potential ways to reduce CEs in each province is of great significance for achieving China's CEs reduction targets.

To solve the above problems, this paper first analyzed the evaluation trends and driving forces of China's and provincial CEs during 1997-2017. Then, three scenarios were constructed to estimate the evolution trend of China's CEs in different scenarios during 2017-2040. Furthermore, LMDI method was used to assess the main driving forces for the dynamics of China's CEs during 2017-2040. Finally, ST-LMDI model was used to evaluate the CEs reduction potential of each province in different scenarios. In particular, this paper analyzed the relative contribution of the proportion of fossil energy in total energy consumption to CEs to indirectly illustrate the effect of non-fossil energy consumption on CEs changes. As this paper covered main types of primary energy sources including fossil and non-fossil energy, impacts of technological progress and nonfossil energy substitution can be presented. This supplemented more detailed information for assessing the potential for future CEs reduction, and provided new evidences for relevant government departments to make decisions.

The reminder of this paper was as follows. Section 2 presents an overview of existing relevant research. Section 3 introduces Kaya identities, Scenario analysis, decomposition analysis and the data sources. Section 4 provides the results. And section 5 concludes the research and gives the policy recommendations.

\section{Literature review}

Many researchers have focused on the issue of China's CEs through different kinds of models such as decomposition (IDA and SDA) model (Huang et al., 2019; Wang and Zhou, 2018), STIRPAT model (Zhang et al., 2017; Zhang and Zhao, 2019), decoupling indicator (Tang et al., 2018; Wang et al., 2018b), and regression analysis (Long et al., 2017; Wen and Liu, 2016). Logarithmic Mean Divisia Index (LMDI) model was used by many scholars to identify the impact factors of CEs (Liu et al., 2019b; Zhang et al., 2018). (Li et al., 2017a; Liu et al., 2019a; Wang et al., 2015; Xu et al., 2014) analyzed influencing factor of China's CEs. The results showed that economic activity was the major force for the growth of CEs. (Chen et al., 2019; Li et al., 2017b; Wang et al., 2016a) explored the drivers of China's growth of CEs. Results showed that energy intensity was the dominant driver to restrain the growth of CEs. Previous studies have fully demonstrated that economic activity and energy intensity are the main driving forces in promoting and curbing China's growth of CEs. Furthermore, an increasing number of scholars have shifted their focus to CEs at the regional level. (Song et al., 2021) studied the dynamics of China's provincial CEs and found that the CEs center shifted from east to west China during 2000-2017. (Wang and Feng, 2017) explored the drivers of CEs changes at China's 
provincial level and found that the influencing factors vary greatly among different provinces. (Jiang et al.,

2017) analyzed the differences in the impact factors of CEs growth of various provinces, and found that Shanxi,

Anhui, and Hebei have made increased contributions on China's growth of CEs.

These studies have conducted extensive discussions on historical CEs changes. However, there is limited researches on the potential evaluation trends and driving factors of future CEs. (Zhang et al., 2019) assessed the influencing forces affecting growth of CEs in China during 2000-2016, and estimated the decline trend in CI in 2020 and 2030. It was found that energy intensity was the leading factor for CEs reduction, and industrial structure optimization would have an important impact on 2020-2030 CEs reduction. (Sun et al., 2019) found that benefiting from non-fossil energy consumption, China's CI can be reduced by up to $72.7 \%$ in 2030 compared to 2005. Some studies have predicted the CEs of a single province in China. (Zhang et al., 2017) predicted that future emission pattern of Henan province will show an increasing initially and follows by a downward trend, which mainly depended on the population growth rate and changes in per capita GDP. (Wang et al., 2019) found that based on the continuous economic development and urbanization process, CEs in Guangdong will maintain a growth trend in 2015-2030. (Qin et al., 2019) predicted the changes of CEs in Xinjiang and found that its CEs will peak at 626.21-662.25Mtons in 2030-2040. (Yu et al., 2019) predicted the CEs reduction in the Beijing-Tianjin-Hebei region up to 2030, and found that energy intensity is the key driver for achieving CEs reduction targets. (Wang et al., 2018a) predicted the CI of six provinces of Southeast coast of China, and found that by 2030 , the CI of these provinces will be reduced by $59.1 \%-69.7 \%$ compared to 2005 .

However, existing research is insufficient in predicting China's sub-sectoral CEs and CI, and analyzing the CEs reduction potential at the provincial level. In limited research, (Zhang et al., 2020) estimated the dynamic trends of CEs in 30 provinces up to 2030, and found that most provinces can achieve the CEs reduction target. (Sun et al., 2019) estimated that China's CI can be reduced by up to 72.7\% in 2030 compared to 2005, and Hebei, Shandong, Shanxi, Liaoning, Xinjiang, and Inner Mongolia were the key provinces. However, exciting studies ignore the impact of non-fossil energy and the differences between sectors. Therefore, this paper applied Kaya identities and scenario analysis to predict China's potential CEs of three sub-sectors during 2017-2040 and applied ST-LMDI model to evaluate the influencing factors of CEs reduction in each province.

This paper contributes the literature as follows. First, this paper combined the scenarios of IEA and OECD with the Kaya identities to predict the trend of China's CEs during 2017 to 2040. Previous studies have mainly emphasized the inter-industry differences in historical CEs. Few studies have predicted China's CEs by sectors. Then, this paper applied LMDI method to evaluate the drivers of China's CEs in different scenarios from 2017 to 2040. Finally, ST-LMDI model was applied to explore the potential path for CEs reduction in provincial level. In Particular, this paper considered both fossil and non-fossil energy so that the effects of technological progress and non-fossil energy substitution can be revealed.

\section{Methodology and data}

\subsection{Kaya identities}

Kaya identities has been widely applied in the study related to CEs drivers. This paper utilized different 
Kaya identities to study CEs at both national and provincial levels respectively. At national level, CEs was decomposed into six influencing factors including the carbon coefficient, fossil energy structure, energy consumption structure, energy intensity, activity, and population. At provincial level, to eliminate the influence of geographic factors, this paper chose CI as the research object. CI was decomposed into four drivers including carbon coefficient, fossil energy structure, energy consumption structure, and energy intensity.

$$
\begin{aligned}
& C E=\sum_{i} C E_{i}=\sum_{i} \sum_{n} \frac{C E_{n i}}{F_{n i}} \times \frac{F_{n i}}{F_{i}} \times \frac{F_{i}}{E_{i}} \times \frac{E_{i}}{Q_{i}} \times \frac{Q_{i}}{P_{i}} \times P_{i}=\sum_{i} \sum_{n} C F_{n i} \times E S_{n i} \times T_{i} \times E I_{i} \times A_{i} \times P_{i} \\
& C I_{j}=\frac{C E_{j}}{Q_{j}}=\sum_{i} \sum_{n} \frac{C E_{n i j}}{F_{n i j}} \times \frac{F_{n i j}}{F_{i j}} \times \frac{F_{i j}}{E_{i j}} \times \frac{E_{i j}}{Q_{i j}}=\sum_{i} \sum_{n} C F_{n i j} \times E S_{n i j} \times T_{i j} \times E I_{i j}
\end{aligned}
$$

The definition of each variables are shown in Table 1.

Table 1 The definition of each variables.

\begin{tabular}{cl|cl}
\hline Variables & Definition & Variables & Definition \\
\hline$C E$ & Carbon emissions & $E S$ & Fossil energy structure \\
$C I$ & Carbon emissions GDP per capita & $T$ & Energy consumption structure \\
$F$ & Fossil energy consumption & $E I$ & Energy intensity \\
$E$ & Total energy consumption & $\mathrm{A}$ & Activity \\
$Q$ & Gross domestic product & $P$ & Population \\
$C F$ & Carbon coefficient & $r$ & Growth rate \\
\hline
\end{tabular}

Note: $n=1,2, \ldots, 17$ represents the $n$ type of fossil energy; $i=1,2,3$ represents the $i$ sector (Primary sector, Secondary sector, Tertiary sector); $j=1,2, \ldots, 30$ represents the $j$ province of China.

Where CI means carbon intensity, represented by CEs GDP per capita; $E$ means total energy consumption, equal to the sum of fossil and non-fossil energy consumption; $C F$ means carbon coefficient, equal to the ratio of CEs to energy consumption; ES means fossil energy structure, represented by the proportion of fuel coal, oil, and gas consumption in fossil energy consumption respectively; $T$ means energy consumption structure, represented by the proportion of fossil energy consumption in total energy consumption; EI means energy intensity, represented by energy consumption GDP per capita; $A$ means activity, represented by economic output; $P$ means population, represented by the number of employed population.

\subsection{Scenario analysis}

Scenario analysis is a common method for predicting the future trend of CEs. (Cui et al., 2021) applied scenario analysis to predict the CI of five urban agglomerations in China in 2025. (Zhu et al., 2020) estimated the peak of CEs in China's transportation sector under three scenarios. (Niu et al., 2020) evaluates China's CI in 2030 under different scenarios and finds that under the BAU scenario, China cannot meet its $2030 \mathrm{CEs}$ reduction commitments. According to the scenario analysis method, this study forecasted the CEs of China's three industries and related influencing factors from 2017 to 2040. In different scenarios, the prediction methods for GDP and population are consistent. The relevant forecast data of GDP and population growth rate come from OECD and UN respectively (OECD, 2019; UN, 2018). The GDP and population in year $t$ was calculated in Equation (3) and (4) respectively.

$Q_{i}^{t}=Q_{i}^{t-1} \times\left(1+r_{i}^{Q}\right)$ 
$P_{i}^{t}=P_{i}^{t-1} \times\left(1+r_{i}^{P}\right)$

143 The future employment population of various industries cannot be directly obtained from observational data. This paper assumes that the trend of the proportion of the employed population in each industry to the total population is stable. Thus, this study calculated the average annual growth rate of the employed population in each industry during 1997-2017. And based on this growth rate, this paper calculated the employment population data of each industry in 2040. Therefore, the predicted GDP and employment was shown in Table 2.

Table 2 Predicted GDP and employment in 2025, 2030 and 2040.

\begin{tabular}{lllll}
\hline Variables & & 2025 & 2030 & 2040 \\
\hline \multicolumn{2}{l}{ Population (Million people) } & $1,448.98$ & $1,453.30$ & $1,435.50$ \\
\multirow{2}{*}{ GDP } & Primary & $6,235.14$ & $6,735.70$ & $6,601.32$ \\
(Billion Yuan) & Secondary & $44,049.37$ & $51,608.10$ & $59,490.79$ \\
& Tertiary & $50,662.83$ & $65,194.27$ & $90,661.89$ \\
\hline
\end{tabular}

Based on the forecasts given by World Energy Outlook 2018 (IEA, 2018), three scenarios ware considered in this paper. NPS is the medium scenario, which aims to provide policy recommendations for achieving shortterm energy and emission targets. In addition to considering the policies that have been implemented by the government, the NPS also considered the official goals and goals already mentioned in the plan. The Nationally Determined Contributions of the Paris Agreement provide an important reference for the government's policy making, although some of them have been supplemented or replaced by more specific documents. NPS reflects the impact of climate and environmental policies on CEs based on these agreements and documents. CPS is a baseline scenario that takes into account the potential environmental impact of documents or policies that have been already published. In this scenario, this paper assumes that the government lacks additional incentives to implement low-carbon strategies. Therefore, when the emission reduction target is a range, this paper assumes that the government is more inclined to achieve its lower threshold. SDS is a scenario that aims to achieve the climate change target. This scenario aims to achieve the sustainable development targets proposed by the United Nations (SDGs). The assumptions of each scenarios were shown in Table 3.

Table 3 Assumptions of each scenarios 
NPS NDC GHG targets: achieve peak CO2 emissions around 2030, with best efforts to peak early; lower CO2 emissions per unit of GDP 60-65\% below 2005 levels by 2030 .

NDC energy target: increase the share of non-fossil fuels in primary energy consumption to $20 \%$ by 2030 .

13th Five-Year Plan targets for 2020.

"Made in China 2025" transition from heavy industry to higher value-added manufacturing.

Expand the role of natural gas.

ETS expansion to domestic aviation and selected industry sectors.

Three-year action plan for cleaner air, announced in July 2018.

Energy price reform, including more frequent adjustments in oil product prices and reduction in natural gas price for non-residential consumers.

CPS Action Plan for Prevention and Control of Air Pollution.

ETS for the power sector.

SDS Universal access to affordable, reliable and modern energy services by 2030

A substantial reduction in air pollution

Effective action to combat climate change: to hold the increase in the global average temperature to well below $2{ }^{\circ} \mathrm{C}$ above pre-industrial levels.

3.3 Decomposition Analysis

\subsubsection{LMDI Method}

As mentioned above, IDA model was widely utilized in the research related CEs reduction. In this paper, we applied additive LMDI model to evaluate the specific influence of various drivers on the evolution trend of China's CEs. Therefore, the evaluation trend of CEs can be expressed as Equation (5).

$\Delta C E=C E^{t}-C E^{0}=\Delta C F+\Delta E S+\Delta T+\Delta E I+\Delta A+\Delta P$

Where $\triangle C E$ stands for the evaluation of China's CEs during this period; $C E^{t}$ and $C E^{0}$ stands for China's CEs in year $t$ and year 0 respectively; $\triangle C F, \Delta E S, \Delta T, \Delta E I, \Delta A$ and $\Delta P$ stands for the changes of China's CEs derived from various drivers. The impact of each driver can be calculated as Equation (6)-(11).

$\Delta C F=\sum_{i} \sum_{n}\left[\left(C E_{n i}^{t}-C E_{n i}^{0}\right) /\left(\ln C E_{n i}^{t}-\ln C E_{n i}^{0}\right)\right] \times\left(\ln C F_{n i}^{t}-\ln C F_{n i}^{0}\right)$

$\Delta E S=\sum_{i} \sum_{n}\left[\left(C E_{n i}^{t}-C E_{n i}^{0}\right) /\left(\ln C E_{n i}^{t}-\ln C E_{n i}^{0}\right)\right] \times\left(\ln E S_{n i}^{t}-\ln E S_{n i}^{0}\right)$

$\Delta T=\sum_{i} \sum_{n}\left[\left(C E_{n i}^{t}-C E_{n i}^{0}\right) /\left(\ln C E_{n i}^{t}-\ln C E_{n i}^{0}\right)\right] \times\left(\ln T_{n i}^{t}-\ln T_{n i}^{0}\right)$

$\Delta E I=\sum_{i} \sum_{n}\left[\left(C E_{n i}^{t}-C E_{n i}^{0}\right) /\left(\ln C E_{n i}^{t}-\ln C E_{n i}^{0}\right)\right] \times\left(\ln E I_{n i}^{t}-\ln E I_{n i}^{0}\right)$

$\Delta A=\sum_{i} \sum_{n}\left[\left(C E_{n i}^{t}-C E_{n i}^{0}\right) /\left(\ln C E_{n i}^{t}-\ln C E_{n i}^{0}\right)\right] \times\left(\ln A_{n i}^{t}-\ln A_{n i}^{0}\right)$

$\Delta P=\sum_{i} \sum_{n}\left[\left(C E_{n i}^{t}-C E_{n i}^{0}\right) /\left(\ln C E_{n i}^{t}-\ln C E_{n i}^{0}\right)\right] \times\left(\ln P_{n i}^{t}-\ln P_{n i}^{0}\right)$

In many studies, due to the specific characteristics of energy resources, researchers often assume that the carbon coefficient is constant. Therefore, in this paper, the carbon coefficient effect was ignored, and the impact of the remaining five driving factors on China's CEs changes were evaluated.

\subsubsection{ST-LMDI method}

At the provincial level, to make the CI of different provinces comparable, this paper applied the ST-LMDI 
model to assess the requirements and potential of CEs reduction in different provinces. The ST-LMDI model can analyze the differences between CI of each province and the target value across temporal and spatial dimensions by constructing a benchmark. This is achieved through multi-region (M-R) comparative analysis. In this paper, the projected CI in 2040 of the three scenarios was established as the benchmark. Then, the CI of each province in 2017 was compared with the benchmark respectively. The specific calculation method was shown as Equation (12).

$\Delta C I_{j}=C I_{j}^{t} / C I_{\mu}=\Delta C F_{j} \times \Delta E S_{j} \times \Delta T_{j} \times \Delta E I_{j}$

Where $\Delta C I$ stands for the spatial differences of $C I ; C I_{j}$ and $C I_{\mu}$ stands for $C I$ in province $j$ and the benchmark, respectively; $\triangle C F, \Delta E S, \Delta T$, and $\Delta E I$ stands for the spatial differences of $C I$ caused by various factors. Since the decomposition object was an intensity indicator, this paper utilized the multiplicative decomposition method to evaluate the spatial differences of each factor. The specific calculation method were shown in Equation (13)-(16).

$\Delta C F_{j}=\exp \left[\sum_{i} \sum_{n} \frac{L\left(C_{n i j}^{t} / G_{i j}^{t}, C_{n i \mu} / G_{i \mu}\right)}{L\left(C I_{i j}^{t}, C I_{i \mu}\right)} \cdot \ln \left(\frac{C F_{n i j}^{t}}{C F_{n i u}}\right)\right]$

$\Delta E S_{j}=\exp \left[\sum_{i} \sum_{n} \frac{L\left(C_{n i j}^{t} / G_{i j}^{t}, C_{n i \mu} / G_{i \mu}\right)}{L\left(C I_{i j}^{t}, C I_{i \mu}\right)} \cdot \ln \left(\frac{E S_{n i j}^{t}}{E S_{n i u}}\right)\right]$

$\Delta T_{j}=\exp \left[\sum_{i} \sum_{n} \frac{L\left(C_{n i j}^{t} / G_{i j}^{t}, C_{n i \mu} / G_{i \mu}\right)}{L\left(C I_{i j}^{t}, C I_{i \mu}\right)} \cdot \ln \left(\frac{T_{n i j}^{t}}{T_{n i u}}\right)\right]$

$\Delta E I_{j}=\exp \left[\sum_{i} \sum_{n} \frac{L\left(C_{n i j}^{t} / G_{i j}^{t}, C_{n i \mu} / G_{i \mu}\right)}{L\left(C I_{i j}^{t}, C I_{i \mu}\right)} \cdot \ln \left(\frac{E I_{n i j}^{t}}{E I_{n i u}}\right)\right]$

For the same reason, in this section, this paper assumed that the carbon coefficient is constant during studying period. The spatial differences of the carbon coefficient effect on CI have not been evaluated, and the impact of remaining three factors were analyzed.

\subsection{Data description}

Due to the limitations of data acquisition, this paper only studied the data of 30 provinces in China (except Hong Kong, Macau, Taiwan, and Tibet) from 1997 to 2040. The historical GDP and Population data was obtained from "National Bureau of Statistics of China" (NBSC, 1998-2018c). The projected GDP data was from OECD (OECD, 2019) and the projected population data was from the United Nation (UN, 2018). The GDP data of each year was calculated based on the constant prices of sub-sector of each province and in 2010 . The historical fossil energy data was obtained from “China Energy Statistics Yearbook” (NBSC, 1998-2018b). The historical non-fossil energy data was acquired from "China Electricity Statistical Yearbook" (NBSC, 1998-2018a). Besides, the projected fossil and non-fossil energy data were both acquired from "World Energy Outlook 2018" published by IEA (IEA, 2018). According to (Yuan et al., 2018), the economic indicator of power generation (tce/kwh) was utilized to convert the power generation by non-fossil energy (kwh) to energy consumption (tce). According to the method published by the IPCC in 2006 (IPCC, 2006), historical CEs was calculated based on fossil energy consumption data. This paper considered four types of energy including fuel coal, fuel oil, fuel gas, and non-fossil energy. 


\section{Results}

4.1 Evaluation trend and drivers of China's carbon emissions

China's CEs increased dramatically from 2931.6Mtons to 9865.83Mtons during 1997 to 2017, with an average annual growth rate of $6.26 \%$ (Fig. 1). This process can be divided into four stages according to growth of CEs characteristics. The first stage is 1997-2002. CEs growth at this stage is relatively slow, with an average annual growth rate of $3.69 \%$. The second stage is 2002-2007. During this period, the CEs increased significantly, with an average annual growth rate of $14.19 \%$. The third stage is $2007-2012$. The CEs growth at this stage is relatively flat, with an average annual growth rate of $6.85 \%$. The fourth stage is $2012-2017$. The CEs hardly increased, with an average annual growth rate of $0.77 \%$. From an industry perspective, the CEs of different industries varied greatly. The primary industry's CEs increased from 76.7Mtons in 1997 to 139.44Mtons in 2017, with an average annual growth rate of 3.03\%. The secondary industry's CEs increased from 2447.1 Mtons in 1997 to 8261.85 Mtons in 2017, with an average annual growth rate of $6.27 \%$. The tertiary industry's CEs increased from 407.8Mtons in 1997 to 1464.54Mtons in 2017, with an average annual growth rate of $6.60 \%$. From proportion perspective, the secondary industry contributed the most to CEs, accounting for $83.74 \%$ of national total in 2017 . The tertiary industry has the fastest growth rate. In 1997 , the tertiary industry accounted for $13.91 \%$ of the national total CEs. However in 2017, this proportion rose to $14.84 \%$. The proportion of the primary industry's CEs in the national total has dropped significantly from $2.62 \%$ in 1997 to $1.41 \%$ in 2017.

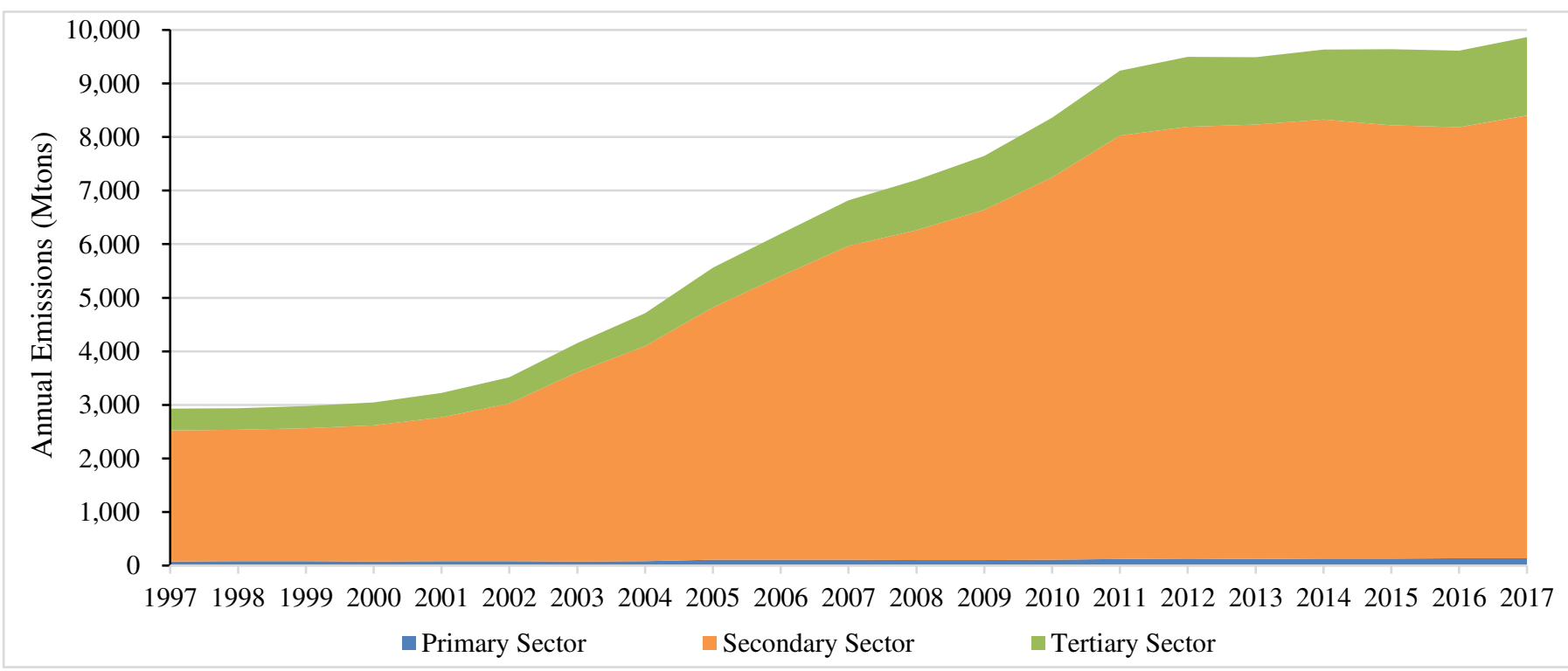

Fig. 1 China's CEs during 1997-2017

LMDI model was applied to analyze the drivers of China's CEs growth in these four period. Results were shown in Fig. 2. From 1997 to 2002, due to the slow development of energy structure optimization and nonfossil energy application, the effects of fossil energy structure and energy consumption structure hardly inhibited growth of CEs in various industries. Energy intensity effect was the leading driver for all three industries to restrain the growth of CEs. Benefiting from technological progress, the energy efficiency of the secondary and tertiary industries has been significantly improved. Energy intensity has reduced the CEs in secondary and tertiary industries by $42.19 \%$ (-1022.85Mtons) and 33.49\% (-136.13Mtons) in this period, 
respectively. While it only reduces the CEs of the primary industry by $11.21 \%$ (-8.56Mtons). Activity effect was the leading force to promote the growth of CEs. From 1997-2002, the average annual growth rate of value added in secondary and tertiary industries was $9.12 \%$ and $9.62 \%$, while that of the primary industry was only $2.88 \%$. Therefore, the promoting role of activity effect on CEs in secondary (1693.65Mtons, 69.87\%) and tertiary industries (162.34Mtons, 39.94\%) was much greater than that of the primary industry (11.85Mtons, $15.53 \%$ ). The population effect is positively correlated with changes in the employment number in various industries. During this period, the employment number in primary and tertiary industries increased by $5.17 \%$ and $13.70 \%$. Therefore, the population effect increased the CEs of primary and tertiary industries by $5.5 \%$ (4.20Mtons) and $13.87 \%$ (56.37Mtons) respectively. However, due to the development of industrialization process, the employment number in secondary industry dropped by $5.23 \%$ during this period. This also led to a population effect that reduced the secondary industry's CEs by $6.57 \%$ (-159.31Mtons).

From 2002 to 2007, due to the rapid expansion of the industries, the employees and the added value of the secondary and tertiary industries increased rapidly, which became the main reason for promoting the growth of CEs. Population and activity effect promoted the secondary industry's CEs growth by $35.58 \%$ (1037.29Mtons) and 20.60\% (100.02Mtons), and promoted the tertiary industry's CEs growth by $70.35 \%$ (2050.70Mtons) and 58.77\% (285.38Mtons). But for the primary industry, due to the continuous reduction of employees, the population effect reduced its CEs by $19.48 \%$ (-16.26Mtons). At this stage, various industries paid their attention to scale expansion, ignoring energy structure improvement and technological progress. Therefore, the effect of fossil energy structure, energy consumption structure, and energy intensity on CEs changes were not significant.

From 2007 to 2012, the scale of each industry continued to expansion, and the value added of each industry grew rapidly. Activity effect became the main driver for promoting the CEs growth, which promoted primary industry's CEs by 43.92\% (48.22Mtons), secondary industry's CEs by 56.47\% (3290.39Mtons), and tertiary industry's CEs by $50.28 \%$ (427.29Mtons). Due to the increasing employment number, population effect also promoted the growth of CEs in secondary (16.35\%, 952.66Mtons) and tertiary (15.65\%, 133.03Mtons) industries. Benefiting from the continuous improvement of mechanization, the employment number in primary industry gradually decreased, and the population effect inhibited CEs growth in primary industry by $19.01 \%$ (-20.87Mtons). Besides, during this period, due to the transformation from extensive to energy-saving especially in secondary industry, energy intensity dramatically curbed the growth of CEs from the primary industry by $6.2 \%$ (-6.8Mtons), from the secondary industry by $32.61 \%$ (-1900.22Mtons), and from third industry's by $11.28 \%$ (-95.87Mtons). Particularly, benefiting from the application of non-fossil energy in secondary industry, the energy consumption structure effect has slightly restrained the growth of CEs in secondary industry $(2.23 \%,-129.70 \mathrm{Mtons})$.

From 2012 to 2017, due to the implementation of environmental protection policies and the improvement of energy efficiency, energy intensity was the dominant driver restraining the CEs growth, which restrained CEs growth from the primary industry by $15.14 \%$ (-19.73Mtons), secondary industry by $6.77 \%$ (543.31Mtons), and tertiary industry by $36.39 \%$ (-475.69Mtons). Activity effect was the main driver promoting 
growth of CEs especially in primary industry (46.99\%, 61.23Mtons). Benefiting from poverty alleviation and agricultural policies, output value of primary industry has grown rapidly at this stage. Besides, activity effect promoted CEs growth from secondary industry by $12.76 \%$ (1024.85Mtons), and tertiary industry by $23.69 \%$ (309.65Mtons) respectively. It is worth noting that there has been a clear labor transfer between industries at this stage. A large amount of labor resources have been transferred from primary to tertiary industry. This caused the population effect to promote the tertiary industry's CEs by $25.68 \%$ (335.70Mtons), while inhibited the primary industry's CEs growth by $24.66 \%$ (-32.13Mtons). For the secondary industry, energy consumption structure $(1.9 \%,-152.54 \mathrm{Mtons})$ and population $(1.40 \%,-112.25 \mathrm{Mtons})$ effect respectively had a slight inhibitory effect.

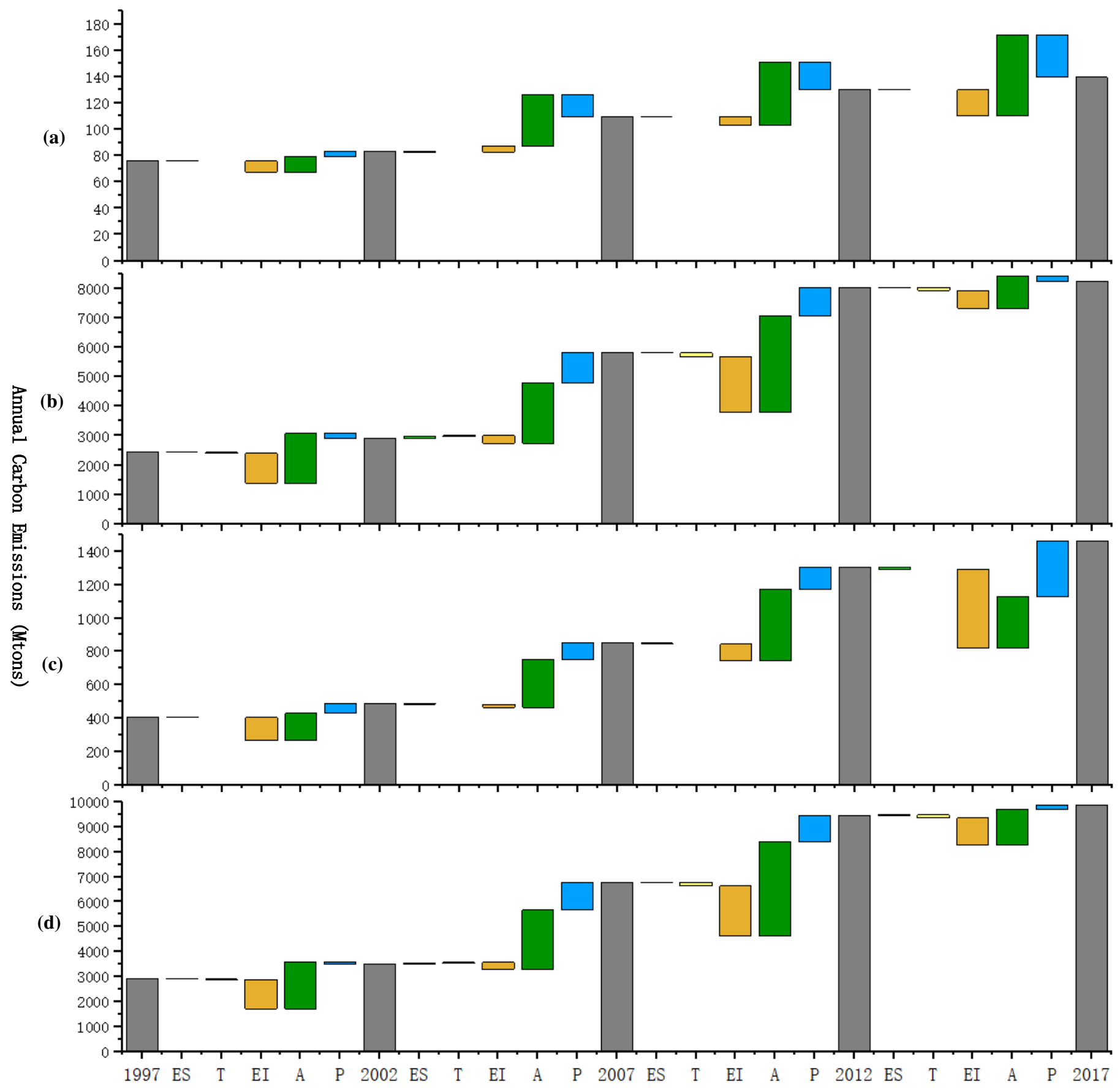

Fig. 2 Decomposition result of historical CEs during 1997-2017 (a) Primary Sector; (b) Secondary Sector; (c) Tertiary Sector; 
303

304

305

306

307

308

309

310

311

312

313

314

315

316

317

318

319

4.2 Scenario analysis of China's carbon emissions

According to the assumptions in section 3.2, this paper predicted the CEs in China during 2017-2040. Fig. 3 and Fig. 4 presented the evolution trend of CEs and CI of various industries in different scenarios from 2017 to 2040 respectively. In the current policies scenario (CPS), China's CEs show an overall upward trend and reach 10729.00Mtons in 2040. The CI continues to decrease from $0.144 \mathrm{Mt} / \mathrm{By}$ in 2017 to $0.085 \mathrm{Mt} / \mathrm{By}$ in 2030 and $0.068 \mathrm{Mt} / \mathrm{By}$ in 2040. Thus, the total CEs of China do not reach the peak before 2040, and the $2030 \mathrm{CI}$ reduction target does not be achieved. From an industrial perspective, the increase in CEs is dominantly attributed to tertiary industry. The CEs increase from 1464.54Mtons in 2017 to 2048.59Mtons in 2040. This is mainly due to the process of industrial upgrading. Benefiting from the dramatically expansion of the industries, the proportion of the tertiary industry will rise from $46.04 \%$ in 2017 to $57.84 \%$ in 2040 .

In the new policies scenario (NPS), China's CEs continue to grow and reach the peak of 9917.79Mtons in 2030. Then, the CEs begin to decline and reach 8584.45Mtons in 2040. It is worth noting that CEs from the tertiary industry continue to increase from 1464.54Mtons in 2017 to 1601.1Mtons in 2040. The key to helping China's CEs peak in 2030 is the secondary industry. From 2017 to 2030, the CEs of secondary industry drop from $8261.85 \mathrm{Mtons}$ to $7946.47 \mathrm{Mtons}$. The CI continues to decrease to $0.080 \mathrm{Mt} / \mathrm{By}$ in 2030, with a decrease rate of $60.19 \%$ compared to that of 2005 . This also means that China achieves the lower limit of $2030 \mathrm{CEs}$ reduction target.

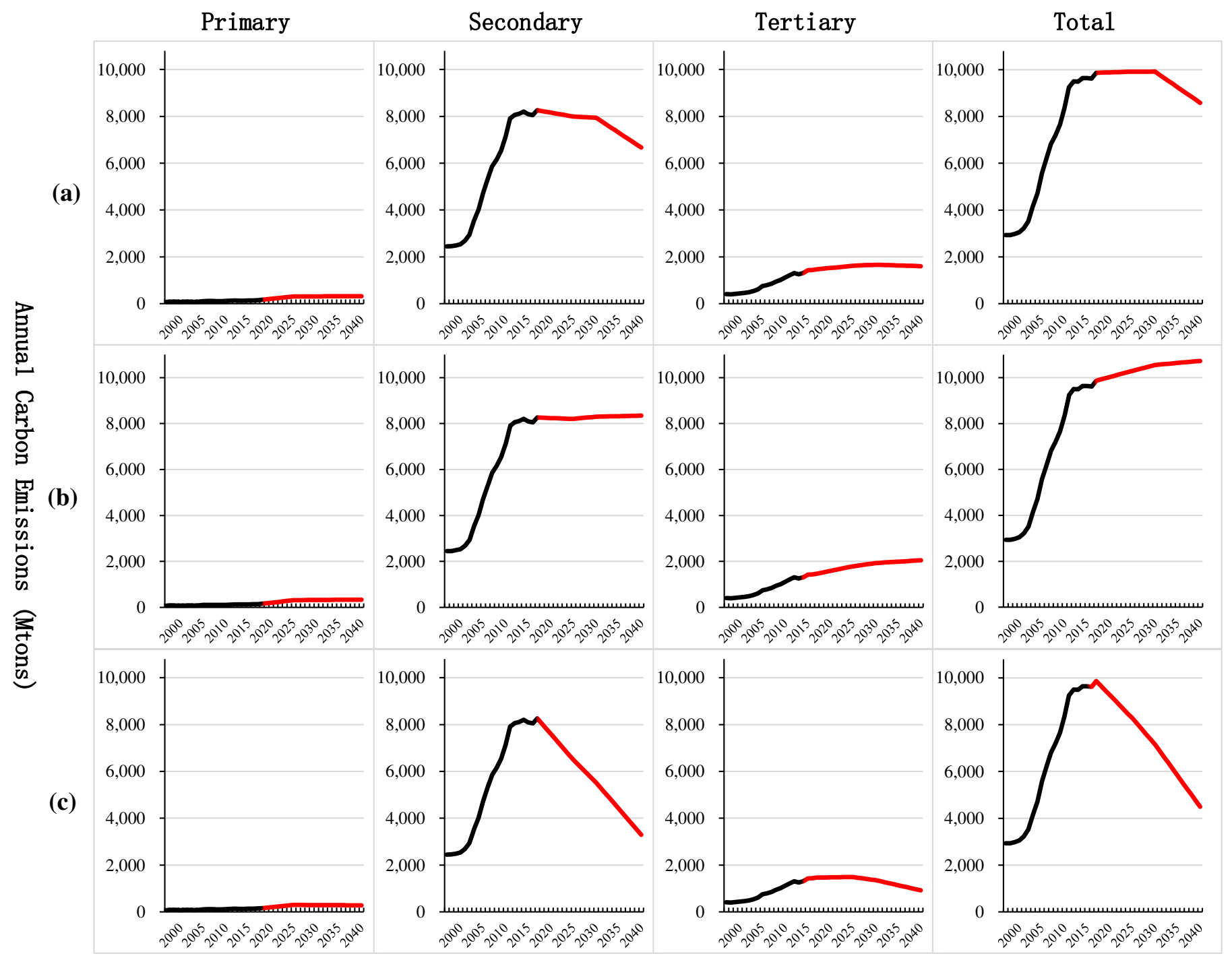


Fig. 3 China's CEs during 1997-2040 in different sector. (a) New Policies Scenario; (b) Current Policies

In the sustainable development scenario (SDS), the CEs continuously decrease from 2017 to 2040 . This is mainly caused by the significant drop of CEs from the secondary industry. Subject to strict energy consumption and emission policies, from 2017 to 2040, the proportion of fossil energy consumption in secondary industry dropped from $87.14 \%$ to $48.98 \%$, and the energy intensity decreased from $0.11 \mathrm{Mt} / \mathrm{By}$ to $0.05 \mathrm{Mt} / \mathrm{By}$. It caused that CEs in secondary industry dropped from 8261.85Mtons to 3294.29Mtons. Particularly, the CEs of the primary and tertiary industries have shown an increasing trend between 2017 and 2025. This means that the energy and emission policies of the government are lagging in primary and tertiary industries, and the relevant policies mainly have effects on the secondary industry. Besides, the CI decreased to $0.058 \mathrm{Mt} / \mathrm{By}$ in 2030 , with a decrease rate of $72.46 \%$ compared to that of 2005. This means that China better achieves its 2030 CEs reduction target, and sustainable energy and industrial policies can play a huge role on environmental improvement and energy conservation.

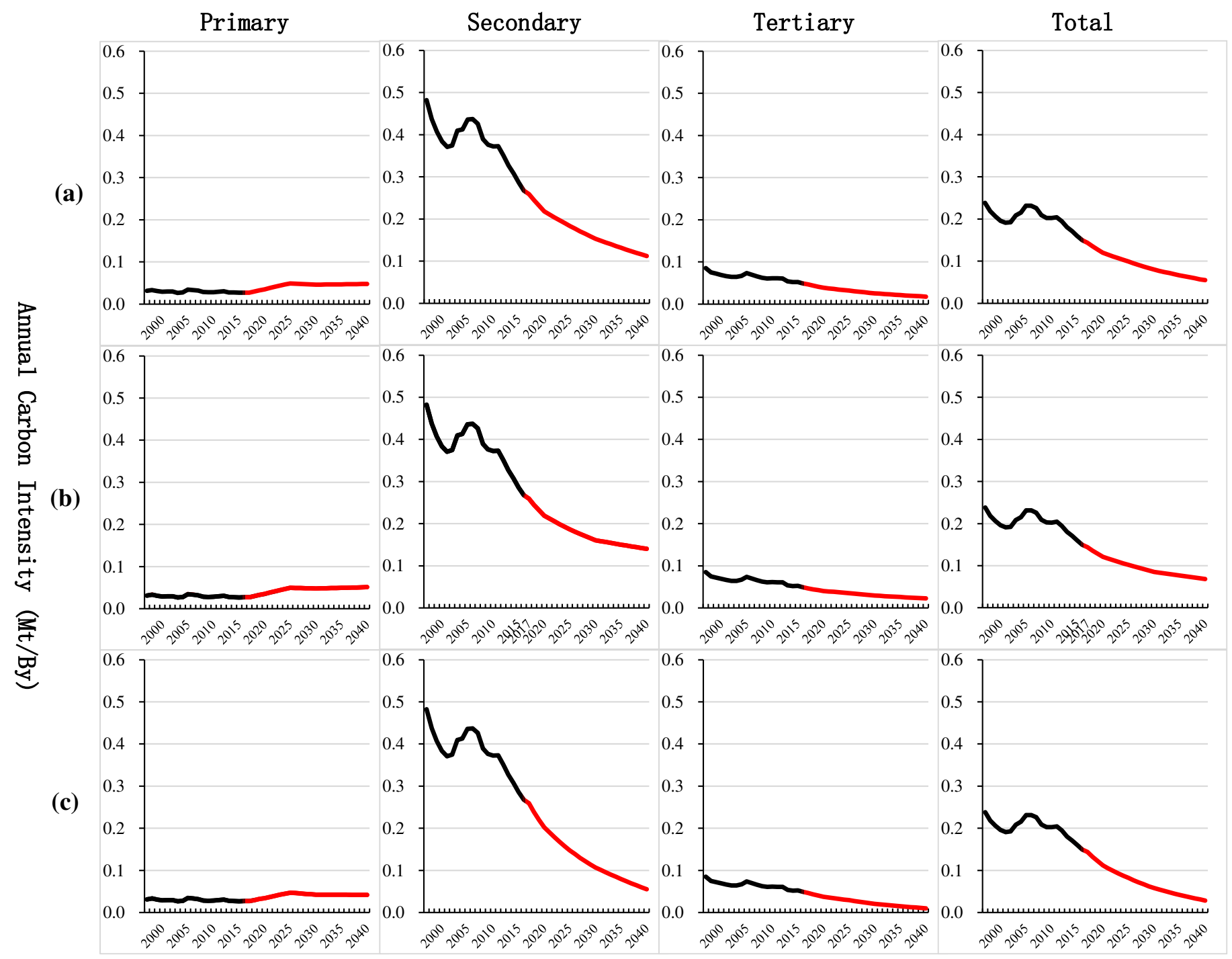

Fig. 4 China's CI during 1997-2040 in different sector. (a) New Policies Scenario; (b) Current Policies Scenario; (c) Sustainable Development Scenario.

According to the LMDI method, this paper analyzed China's CEs in different scenarios during 2017-2040 at industrial level. The decomposition results are shown in Fig.5. In the current policies scenario (CPS), with 
the rapid expansion of the scale of the industry, the activity effect promotes the continuous growth of China's CEs, which respectively contributes to CEs increasing by $191.80 \%$ (267.79Mtons) in primary industry, $26.38 \%$ (2179.27Mtons) in secondary industry, and 55.89\% (818.49Mtons) in tertiary industry. In view of the targeted energy policies for energy-intensive industries, energy intensity as a leading force reduces CEs in secondary industry by $17.19 \%$ (-1420.18Mtons), and in tertiary industry by 50.98\% (-1993.59Mtons). However for primary industry, due to the increase of energy consumption, energy intensity promotes the CEs growth by $124.04 \%$ (173.18Mtons). With the application of non-fossil energy, energy consumption structure effect inhibits the CEs growth in primary industry by $3.03 \%$ (-4.23Mtons), the secondary industry by $4.95 \%$ (408.71Mtons), and the tertiary industry by $14.95 \%$ (-218.87Mtons). The result of population effect is a manifestation of labor transfer between industries. From 2017-2040, the employment number in primary and secondary industries decreases by $75.71 \%$ and $11.38 \%$, while the employment number in tertiary industry increased by $60.72 \%$. This is in line with the trend of agricultural mechanization and industrial intelligence. It is worth noting that the fossil energy structure has a 2.9\% (239.79Mtons) promotion effect on CEs growth in secondary industry. It means that current fossil energy policy cannot curb growth of CEs process.

In the new policies scenario (NPS), activity effect is still the main impact factor, which increases CEs in primary industry by $183.37 \%$ (256.02Mtons), secondary industry by $36.96 \%$ (3052.83Mtons), and tertiary industry by $53.5 \%$ (783.46Mtons). In NPS, the government implements a series of stricter energy consumption and energy substitution policies. Energy intensity effects have a more obvious effect on CEs decrease in secondary (32.96\%, -2722.41Mtons) and tertiary (66.87\%, -979.33Mtons) industries. The new policies require the non-fossil energy consumption to reach $24.85 \%$ in 2040 , which reduce CEs by $3.08 \%$ (-4.3Mtons) in primary industry, $13.60 \%$ (-1123.07Mtons) in secondary industry, and $19.17 \%$ (-280.70Mtons) in tertiary industry. Besides, the proportion of coal consumption drop to $45.36 \%$ in 2040 . This makes the fossil energy structure effect slightly reduce the CEs from the secondary industry (1.07\%, -88.32Mtons). Compared with the development of non-fossil energy, the impact of fossil energy structure optimization on CEs reduction is limited.

In the sustainable development scenario (SDS), the activity effect on CEs growth is further suppressed, increasing CEs in primary industry by $169.67 \%$ (236.89Mtons), in secondary industry by $30.51 \%$ (2520.03Mtons), and in tertiary industry by $39.30 \%$ (575.60Mtons). Energy policies in SDS further reduce the energy intensity. In secondary and tertiary industries, energy intensity effect reduces CEs by $41.77 \%$ ($3450.21 \mathrm{Mtons})$ and $80.54 \%$ (-1179.45Mtons), respectively. Due to the substantial decline in coal consumption and the increase of non-fossil energy consumption, fossil energy structure and energy consumption structure effects have had significant effects in reducing CEs. Especially for the energy consumption structure effect, in SDS, the proportion of the non-fossil energy consumption is $44.33 \%$ in 2040 , which results in a reduction of CEs by $6.26 \%$ (-8.74Mtons) in primary industry, 33.84\% (-2794.70Mtons) in secondary industry, 21.25\% (-311.21Mtons) in tertiary industry. This further proves that vigorously developing non-fossil energy is of great significance for achieving CEs reduction targets. 


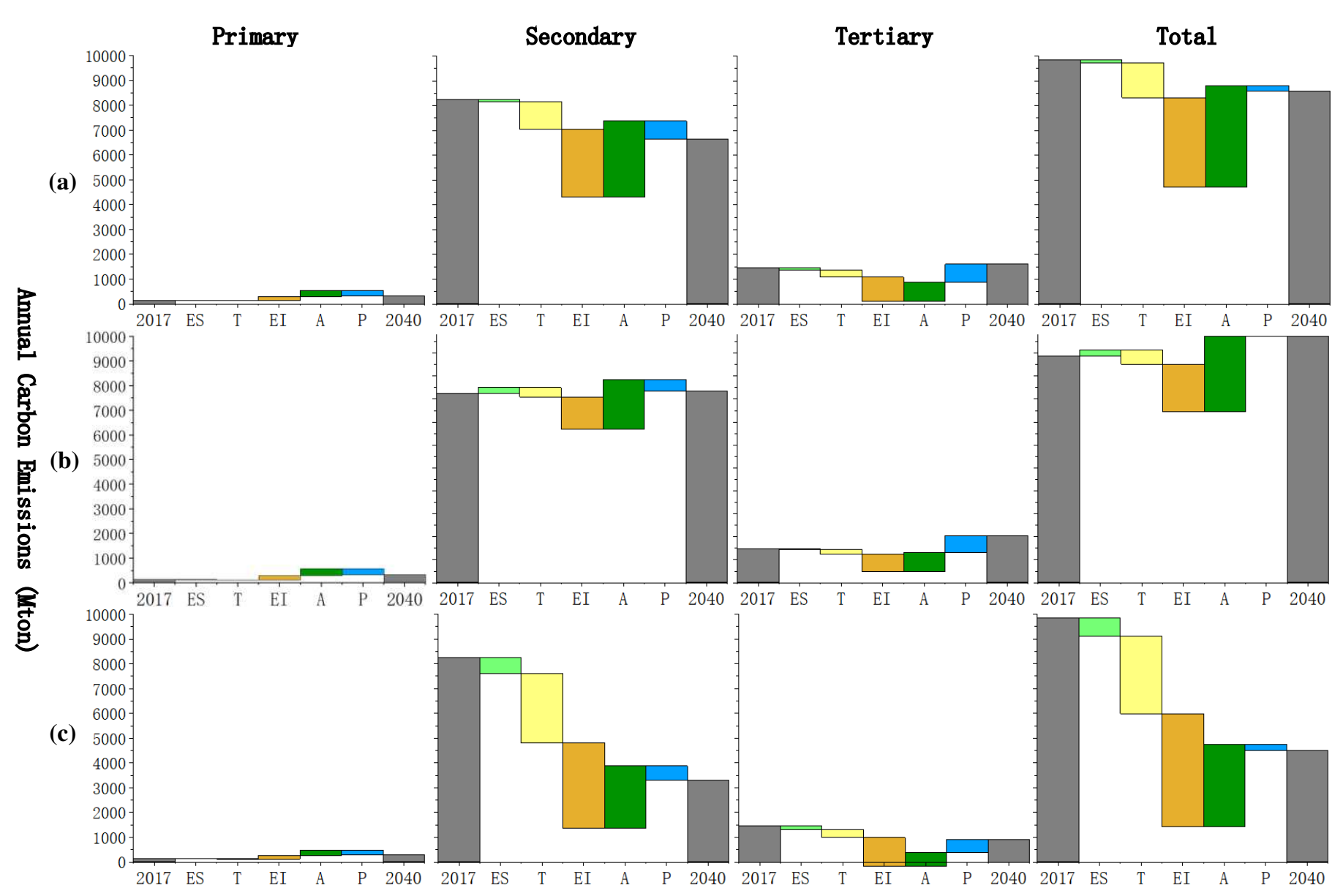

Fig. 5 Decomposition result of China's CEs during 1997-2040 in different sector. (a) New Policies Scenario; (b) Current Policies Scenario; (c) Sustainable Development Scenario.

4.4 Provincial emission analysis

\subsubsection{Evaluation trend of provincial emissions}

The dynamic of provincial CEs during 1997-2017 was shown in Fig. 6. The CEs have undergone different evolutionary trends at the provincial level during 1997-2017. In primary industry, due to the continuous expansion of the industry, most provinces have experienced rapid growth in CEs except Beijing, Shanxi, Shanghai, Chongqing and Guizhou. The decrease in fuel coal consumption led to CEs reduction of Shanxi, Shanghai, Chongqing and Guizhou by $46.23 \%, 95 \%, 70.34 \%$ and 30\%, respectively. For Beijing, the CEs reduction was mainly due the decrease of fuel oil consumption. On the contrary, during this period, Hebei, Inner Mongolia, Heilongjiang and Sichuan had the largest CEs growth in the primary industry, which increased by $4.54 \mathrm{Mtons}$ (189.17\%), 10.56Mtons (440.00\%), 7.51Mtons (144.42\%) and 4.14Mtons respectively (591.43\%). It is mainly caused by the growth of fuel coal and fuel oil consumption. In secondary industry, only CEs in Beijing declined between 1997 and 2017. This is mainly due to the shutdown or transfer of energyintensive industries, which is Beijing's great achievement in easing the functions of the capital (Liu et al., 2019b). The CEs of secondary industry in other provinces have experienced different degrees of growth especially for Hebei, Inner Mongolia, Jiangsu and Shandong. With the rapid increase in industrial output value, industrial energy, especially coal consumption in various provinces has increased significantly (Qiao et al., 2019). This directly causes a growth of CEs. In tertiary industry, the CEs of all provinces showed a clear upward trend, which is consistent with the continuous expansion of the tertiary industry. Especially in 


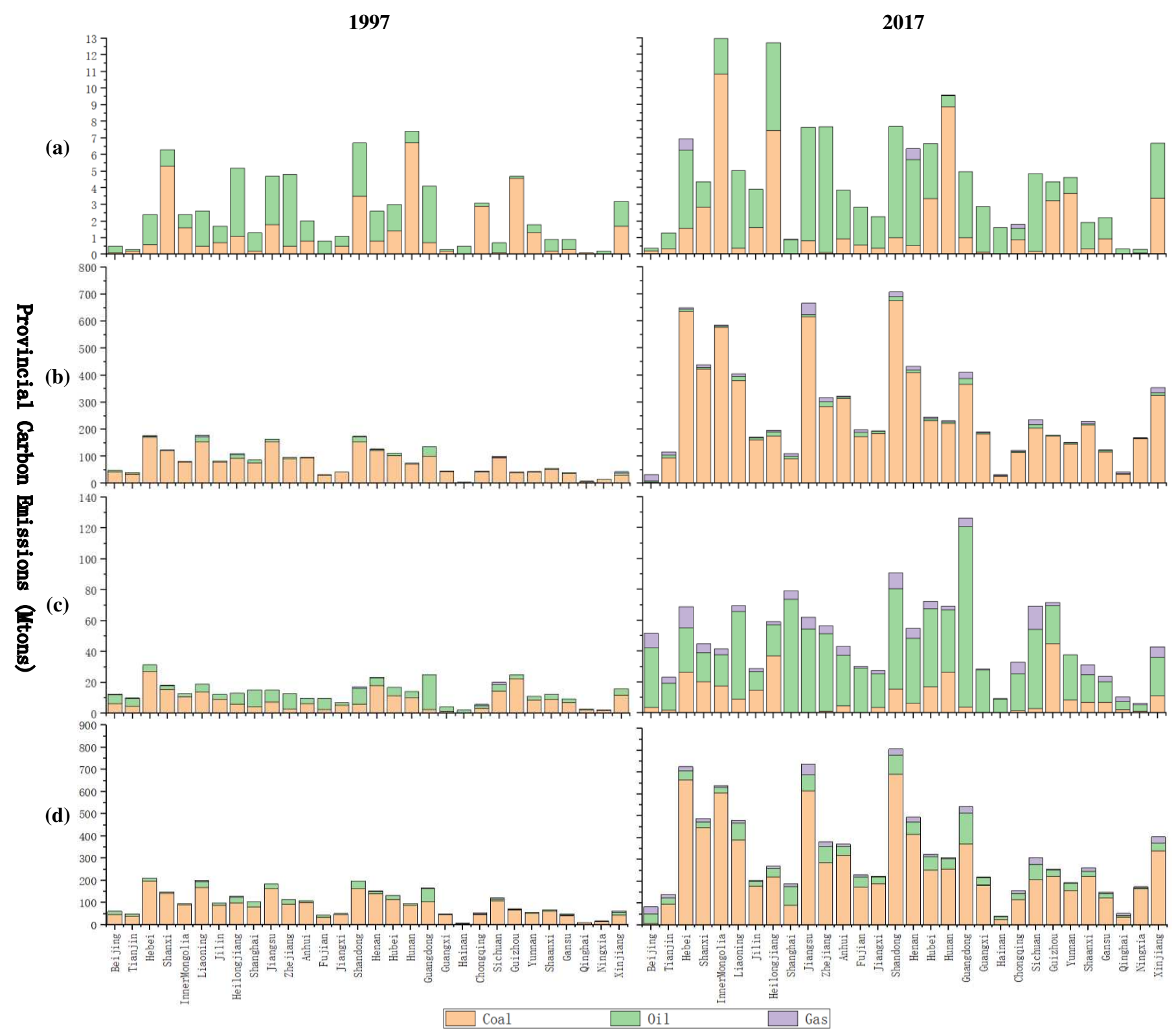

developed provinces such as Beijing, Shanghai, Jiangsu, Zhejiang, Shandong and Guangdong, rapid development of the tertiary industry has also driven their energy related CEs to grow rapidly by $314.24 \%$ (39.28Mtons), $416.67 \%$ (63.75Mtons), $311.72 \%$ (47.07Mtons), $345.43 \% \quad$ (43.87Mtons), $424.57 \%$ (73.45Mtons), and 401.23\% (101.11Mtons) respectively. In particular, there are clear differences in the CEs growth pattern among secondary and the tertiary industries. The CEs growth of secondary industry mainly derived from coal consumption, while that of the tertiary industry mainly derived from oil consumption (Wang et al., 2019).

Fig. 6 Provincial CEs during 1997-2017 (a) Primary Sector; (b) Secondary Sector; (c) Tertiary Sector; (d) National Total.

Fig. 7 showed the changes on CI at the provincial level from 1997 to 2017. Form 1997-2002, the CI of most provinces declined except Shanxi, Hainan and Ningxia. This is mainly affected by the secondary industry. Only the secondary industry's CI in Hainan and Ningxia increased between 1997 and 2002. Particularly, the CI of various industries in Shanxi showed a downward trend during this period. However, due to the significant growth in the proportion of the secondary industry, its CI has increased slightly. From 2002 to 2007, the CI of 18 provinces showed an increasing trend. Especially for Fujian, Shandong and Yunnan, the growth rate of CI was all above $30 \%$. This is the result of extensive economic development. It is worth noting that the CI of 
Beijing and Shanghai both decreased more than 20\% during this period, especially the CI of the secondary industry, which decreased more than 30\%. It depends on the city positioning of Beijing and Shanghai. As an international metropolis, Beijing and Shanghai have been committed to alleviating energy-intensive industries, but these policies has also led to the CEs growth in neighboring provinces (Sun et al., 2019). From 2007-2012, local governments introduced a series of environmental and energy policies, and only Ningxia and Xinjiang showed a growth in CI. It is dominantly caused by the increase of CEs of secondary industry. Due to the relatively backward development, the economic growth of Ningxia and Xinjiang is more dependent on resource-driven development of the coal industry, which has caused the continuous increase of CEs. From 2012-2017, only CI in Xinjiang showed a growth trend. Moreover, from industrial perspective, the CI of the secondary and tertiary industries in most provinces has declined except Xinjiang. Governments should give more policy support to Xinjiang, and develop clean energy in accordance with local conditions to reduce CEs.

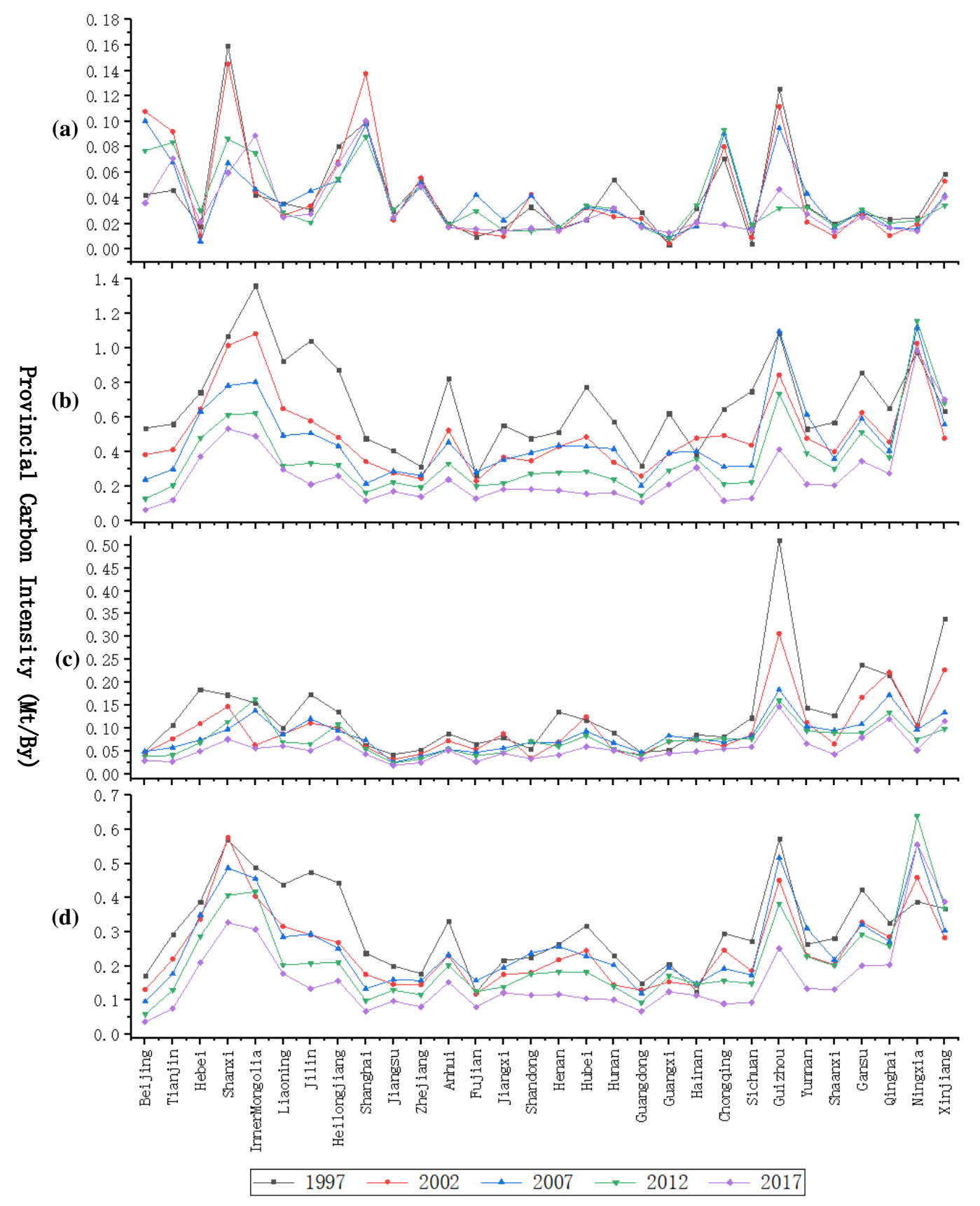

Fig. 7 Provincial CI during 1997-2017 (a) Primary Sector; (b) Secondary Sector; (c) Tertiary Sector; (d) National Total. 


\subsubsection{Provincial decomposition results}

Analyzing the spatial difference of $\mathrm{CI}$ between each province and the ideal state is of great significance for identifying key provinces and assessing potential approaches for CEs reduction. Based on the above analysis, the sustainable development scenario (SDS) is the most ideal scenario. Therefore, in this section, China's average CI in 2040 under the sustainable development scenario is established as a benchmark, and ST-LMDI model was applied to evaluate the spatial differences between provinces and the benchmark. Table 4 presented the spatial-temporal decomposition results. For primary industry, the spatial differences mainly depends on fossil energy structure and energy intensity effects. With the process of agricultural mechanization, modern large-scale agricultural machinery has gradually replaced manpower, leading to a dramatic growth of energy consumption in 2040 (Lin and Liu, 2017). The energy intensity effect of most provinces is lower than the benchmark except Tianjin, Inner Mongolia, Heilongjiang and Shanghai. Inner Mongolia and Heilongjiang are the provinces with the largest energy consumption in primary industry, accounting for about $20 \%$ of national total. Reducing their energy consumption is critical to controlling CEs in primary industry. The energy structure effect of Shanxi, Inner Mongolia, Hunan, Guizhou and Yunnan was higher than that of benchmark. In these provinces, coal consumption accounted for more than $60 \%$ of the energy consumption in primary industry. Increasing oil and gas consumption may significantly reduce their CI of the primary industry. Besides, the energy consumption structure effect of all provinces is higher than the benchmark, and there is no obvious spatial difference among these provinces.

In secondary industry, energy intensity effect is the leading driver for inter-provincial differences of CI. The energy intensity effect of most provinces is higher than the benchmark except Beijing. This indicates that the energy intensity of secondary industry in Beijing is lower than that of the benchmark. As a developed province, Beijing is committed to alleviating non-capital functions, vigorously develop high-tech industries, and eliminate low-value-added energy-intensive industries. On the contrary, the energy intensity effect of Shanxi, Ningxia and Xinjiang is much higher than that of other provinces. Traditional energy-intensive industries have always been pillar industries in Shanxi province, and the economic development of Shanxi is heavily dependent on fossil energy consumption (You et al., 2021). Due to the weak industrial base, the manufacturing industry in Ningxia and Xinjiang developed slowly and their energy efficiency was relative low. Therefore, Shanxi, Ningxia and Xinjiang have great potential for CEs reduction, and promoting industrial upgrading and technological progress is a valid method to decrease their CI. The energy consumption structure effect of most provinces is higher than the benchmark except Yunnan. This is mainly due to the development of hydropower in Yunnan, and its non-fossil energy consumption accounts for much higher proportions than other provinces. Some other studies have also obtained similar results (Xiao et al., 2019; Zhang et al., 2018).

In tertiary industry, the spatial differences mainly derive from energy intensity effect. The energy intensity effects of all provinces are higher than the benchmark, especially Guizhou, Qinghai, and Xinjiang. In these provinces, tourism takes a high proportion of the tertiary industry. However, tourism industry in these provinces is still in a stage of rapid development, and their energy efficiency is relatively low. It is critical to integrating tourism resources and vigorously developing eco-tourism to reduce CEs (Wang et al., 2016b). On the contrary, the CI of tertiary industry in the developed provinces such as Beijing, Tianjin, Jiangsu, Zhejiang, 
and Fujian was relatively low compared to other provinces. This is mainly due to the relatively high consumer demand and the relatively mature development of the service industry in these provinces. The spatial differences of fossil energy structure effect and energy consumption structure effect are similar. All provinces have great potential in optimizing the energy structure. Vigorously developing non-fossil energy sources take a crucial position in decraesing CI.

In general, the GDP of the secondary industry accounts for less than $50 \%$, but related CEs occupy more than $80 \%$ of the national total. Therefore, evolution of CI is mainly affected by the secondary industry. Reducing energy intensity is the most valid method to reduce CEs in all provinces except Beijing. For the secondary industry, there are two major ways to improve energy intensity. The first is to promote technological progress and improve energy efficiency. The second is to optimize the industrial structure and develop modern manufacturing. For provinces dominated by traditional manufacturing, such as Hebei, Jilin, and Liaoning, improving energy efficiency is the most valid method to reduce the CI of secondary industry. For provinces dominated by modern manufacturing such as Tianjin and Jiangsu, improving technological innovation capabilities and developing high-tech industries are of great significance to achieving CEs reduction goals. For Beijing, improving the energy structure and increasing non-fossil energy consumption are the most active method to decrease CEs. The development of clean energy power generation in accordance with local conditions and improving the long-distance transmission capacity of the power grid are essential to promote non-fossil energy consumption.

Table 4 Decomposition result of provincial CI during 2017-2040 in different sector from Sustainable Development Scenario.

\begin{tabular}{|c|c|c|c|c|c|c|c|c|c|c|c|c|}
\hline \multirow[t]{2}{*}{ Provinces } & \multicolumn{3}{|c|}{ Primary } & \multicolumn{3}{|c|}{ Secondary } & \multicolumn{3}{|c|}{ Tertiary } & \multicolumn{3}{|c|}{ Total } \\
\hline & ES & $\mathrm{T}$ & EI & $\mathrm{ES}$ & $\mathrm{T}$ & EI & $\mathrm{ES}$ & $\mathrm{T}$ & EI & ES & $\mathrm{T}$ & EI \\
\hline Beijing & 0.89 & 1.04 & 0.66 & 0.82 & 1.82 & 0.78 & 1.08 & 1.32 & 1.96 & 0.91 & 1.67 & 0.82 \\
\hline Tianjin & 0.63 & 1.03 & 1.06 & 0.96 & 2.02 & 1.24 & 1.09 & 1.32 & 1.79 & 1.03 & 1.78 & 1.59 \\
\hline Hebei & 0.62 & 1.04 & 0.51 & 1.26 & 1.90 & 2.93 & 1.28 & 1.28 & 2.97 & 1.30 & 1.69 & 3.43 \\
\hline Shanxi & 1.02 & 1.05 & 0.93 & 1.21 & 1.94 & 7.72 & 1.49 & 1.27 & 3.88 & 1.26 & 1.71 & 9.09 \\
\hline Inner Mongolia & 1.32 & 1.05 & 1.24 & 1.23 & 1.83 & 4.25 & 1.42 & 1.27 & 3.04 & 1.36 & 1.62 & 5.28 \\
\hline Liaoning & 0.41 & 1.02 & 0.71 & 1.12 & 1.87 & 2.86 & 1.26 & 1.30 & 3.55 & 1.19 & 1.67 & 3.44 \\
\hline Jilin & 0.17 & 1.04 & 0.56 & 1.16 & 1.86 & 1.84 & 1.52 & 1.26 & 2.58 & 1.24 & 1.66 & 2.37 \\
\hline Heilongjiang & 0.95 & 1.04 & 1.01 & 1.16 & 1.91 & 2.32 & 1.85 & 1.24 & 3.48 & 1.21 & 1.70 & 2.86 \\
\hline Shanghai & 0.47 & 1.01 & 1.13 & 0.92 & 2.00 & 1.37 & 1.16 & 1.31 & 2.65 & 1.01 & 1.74 & 1.48 \\
\hline Jiangsu & 0.44 & 1.03 & 0.68 & 1.14 & 1.93 & 1.35 & 1.09 & 1.31 & 1.26 & 1.18 & 1.70 & 1.62 \\
\hline Zhejiang & 0.43 & 1.01 & 0.94 & 1.10 & 1.72 & 1.26 & 1.11 & 1.31 & 1.65 & 1.12 & 1.56 & 1.52 \\
\hline Anhui & 0.52 & 1.03 & 0.48 & 1.23 & 1.90 & 1.84 & 1.14 & 1.31 & 3.37 & 1.25 & 1.70 & 2.47 \\
\hline Fujian & 0.48 & 1.03 & 0.48 & 1.06 & 1.49 & 1.40 & 1.16 & 1.30 & 1.68 & 1.11 & 1.37 & 1.76 \\
\hline Jiangxi & 0.43 & 1.03 & 0.47 & 1.21 & 1.82 & 1.40 & 1.19 & 1.30 & 2.81 & 1.23 & 1.63 & 1.94 \\
\hline Shandong & 0.42 & 1.03 & 0.53 & 0.29 & 1.93 & 1.40 & 1.15 & 1.30 & 2.13 & 1.21 & 1.72 & 1.82 \\
\hline Henan & 0.37 & 1.03 & 0.46 & 1.17 & 1.94 & 1.43 & 1.15 & 1.31 & 2.72 & 1.20 & 1.72 & 1.98 \\
\hline Hubei & 0.79 & 1.04 & 0.48 & 1.19 & 1.37 & 1.64 & 1.29 & 1.29 & 3.51 & 1.18 & 1.33 & 2.20 \\
\hline Hunan & 1.46 & 1.06 & 0.49 & 1.20 & 1.67 & 1.33 & 1.42 & 1.27 & 2.89 & 1.21 & 1.55 & 1.74 \\
\hline Guangdong & 0.49 & 1.03 & 0.50 & 1.06 & 1.70 & 1.04 & 1.17 & 1.30 & 2.08 & 1.08 & 1.56 & 1.34 \\
\hline Guangxi & 0.33 & 1.02 & 0.55 & 1.22 & 1.49 & 1.80 & 1.23 & 1.30 & 2.69 & 1.23 & 1.38 & 2.20 \\
\hline
\end{tabular}




\begin{tabular}{lllllllllllll} 
Hainan & 0.23 & 1.00 & 0.95 & 0.06 & 1.64 & 2.97 & 1.19 & 1.30 & 3.01 & 1.01 & 1.52 & 2.22 \\
Chongqing & 0.86 & 1.05 & 0.36 & 1.16 & 1.74 & 1.05 & 1.06 & 1.32 & 3.71 & 1.12 & 1.60 & 1.68 \\
Sichuan & 0.33 & 1.02 & 0.61 & 1.08 & 1.05 & 2.10 & 1.06 & 1.32 & 3.98 & 1.07 & 1.06 & 2.80 \\
Guizhou & 1.13 & 1.05 & 0.75 & 1.27 & 1.47 & 3.72 & 2.15 & 1.24 & 5.62 & 1.30 & 1.43 & 4.54 \\
Yunnan & 1.17 & 1.05 & 0.47 & 1.21 & 0.86 & 3.56 & 1.42 & 1.28 & 3.57 & 1.23 & 0.88 & 4.06 \\
Shaanxi & 0.45 & 1.03 & 0.46 & 1.14 & 1.93 & 2.53 & 1.15 & 1.30 & 2.76 & 1.16 & 1.71 & 3.23 \\
Gansu & 0.71 & 1.04 & 0.53 & 1.21 & 1.49 & 3.63 & 1.29 & 1.29 & 4.67 & 1.22 & 1.39 & 4.27 \\
Qinghai & 0.46 & 1.03 & 0.53 & 1.01 & 1.17 & 4.08 & 1.16 & 1.31 & 7.62 & 1.04 & 1.14 & 5.83 \\
Ningxia & 0.53 & 1.04 & 0.41 & 0.82 & 1.81 & 8.71 & 1.16 & 1.31 & 3.28 & 1.44 & 1.60 & 9.64 \\
Xinjiang & 0.82 & 1.04 & 0.72 & 1.15 & 1.79 & 6.45 & 1.28 & 1.30 & 6.76 & 1.22 & 1.60 & 7.25 \\
\hline
\end{tabular}

\section{Conclusions and policy recommendations}

This study first analyzed the evolution trend and influencing factors of China's CEs during 1997-2017. Then, scenario analysis was applied to analyze China's CEs and CI at industrial level from 2017 to 2040 in different scenarios. Next, the LMDI model was used to esplore the driving force of China's CEs reduction in different scenarios. Furthermore, this paper analyzed the differences in CEs and CI of various provinces from the provincial level. Finally, the ST-LMDI model was used to explore the CEs reduction potential and potential paths at provincial level based on sustainable development scenario. The main conclusions are as follows.

\subsection{Conclusions}

During 1997-2017, China's CEs growth was continuous, with an average annual growth rate of $6.26 \%$. Secondary industry was the main source of CEs, accounting for more than $80 \%$ of national total. Activity effect was the dominant force for CEs growth. Benefiting from technological progress, energy intensity was a key driver in restraining the growth of CEs. However due to extensive economic development, the restraining effect was not obvious during 2002-2007. Population effect was a key factor for CEs growth in tertiary industry especially during 2012-2017 (25.68\%). With the development of non-fossil energy, the energy consumption structure effect began to curb the CEs growth (-2.23\%) during 2007-2012, and continued to show restraint effect (-1.40\%) during 2012-2017.

In the scenario analysis, different energy and environmental policies have had a clear influence on CEs. In the current policy scenario, China's CEs increase continuously in 2017-2040, and $2030 \mathrm{CI}$ reduction target will not come true. In the new policies scenario, China's CEs will peak at 2030 due to the improvement of energy efficiency and optimization of energy structure. In addition, China's CI will drop by $60 \%$ in 2030 compared to 2005, which means that China will achieve the lower limit of 2030 CEs reduction target. It is dominantly caused by the decrease in CEs from secondary industry. In the sustainable development scenario, CEs continue to decline from 2017-2040. CI will drop by $72.46 \%$ compared to 2005 . This scenario is far better than the other two scenarios in terms of CEs reduction. However, CEs reductions mainly occur in secondary industry. It means that energy efficiency improvement and energy structure optimization have a great effect on the CEs reduction of the secondary industry. But it has limited effects on the primary and tertiary industries.

From provincial level, the CEs have undergone different growth trends at the provincial level during 19972017 except Beijing. This is mainly benefitted from Beijing's efforts to relieve non-capital functions. Due to the expansion of traditional industries, CEs in Inner Mongolia, Heilongjiang, Shandong, and Hebei have 
grown rapidly. The downward trend of CI in Xinjiang, Ningxia and Shanxi is not obvious. It is mainly due to that the economic growth of these provinces is more dependent on resource-driven development of the coal industry. For most provinces, reducing energy intensity is the most effective way to achieve CEs reduction targets. However, for developed provinces such as Beijing and Shanghai, the potential for energy intensity decline is limited. Improving the energy structure and promoting non-fossil energy consumption are potential ways to reduce CEs.

\subsection{Policy recommendations}

Based on the above analysis, some potential measures can be implemented to control China's CEs. In the current policy scenario, existing energy and technology policies are not sufficient to restrain CEs growth. More effective methods should be implemented to reduce energy intensity especially in secondary industry. For provinces dominated by traditional manufacturing, such as Hebei, Shanxi, and Inner Mongolia, improving energy efficiency is the most effective way. While for provinces with a weak industrial foundation, efforts should be made to develop modern industries in accordance with local conditions. Besides, for developed provinces such as Beijing and shanghai, it is essential to develop high-tech industries, further expand investment in low-carbon infrastructure, and advocate low-carbon consumption, which is also in line with the assumption of sustainable development scenarios.

Optimizing the energy structure and promoting non-fossil energy consumption are the keys to ensuring the achievement of CEs reduction targets. From the new policy scenario, the optimization of the energy structure is a crucial driver in the peak of CEs in secondary industry. However, relevant energy structure policies cannot help the CEs of the primary and tertiary industries reach their peak before 2030. Therefore, more measures need to be taken for the optimization of energy structure. On the one hand, more vigorous "coal-to-gas" policies should be extended to more provinces such as Shanxi, Inner Mongolia, Shandong and Ningxia. On the other hand, develop non-fossil energy in accordance with local conditions. For example, Hubei, Chongqing and Yunnan can make full use of their geographical advantages to develop hydro power generation. Striving to achieve non-fossil energy power generation accounting for $50 \%$ of the national total by 2030 (NDRC, 2016).

The development of low-carbon infrastructure and the overall planning of smart grids are important guarantees for de-carbonization. In the sustainable development scenario, CEs from the tertiary industry reach a peak around 2025. This is mainly due to the growth of clean energy especially green power consumption. However, in the current and new policy scenarios, the relevant policies cannot curb CEs growth due to the increase of energy consumption. Therefore, the government should increase relevant investments such as the construction of new energy vehicle charging stations and the laying of long-distance power transmission networks. Reduce obstacles to the promotion of clean energy on the consumer side.

\section{Compliance with Ethical Standards}

Conflict of Interest: The authors declare that they have no conflict of interest.

Author information 
Ce Song, Tao Zhao,

College of Finance, Tianjin University of Finance and Economics, 300222, Tianjin, China

Juan Wang

Corresponding author

Correspondence to CEs Song

554

555

556

557

558

559

560

561

562

563

564

565

566

567

568

569

570

571

572

573

574

575

576

577

578

579

580

581

582

583

584

585

\section{Declarations}

Ethics approval and consent to participate

Not applicable

Consent for publication

Not applicable

Availability of data and materials

The datasets generated and analyzed during the current study are available in the National Bureau of Statistics of China, China Energy Statistics Yearbook, and China Electricity Statistical Yearbook. http://www.stats.gov.cn/tjsj/ndsj/

Competing interests

The authors declare that they have no competing interests

Funding

This work was funded by the Major Program of Social Science Foundation of Tianjin Municipal Education Commission (No. 2016JWZD04) and the Ministry of Education of Humanities and Social Science Research Fund Plan (no. 15YJA790091).

Authors' contributions

CS did the scenario and decomposition analysis, and was a major contributor in writing the manuscript. TZ came up with this research idea and financially supported this work. JW analyzed existing literatures and provided a lot of work for the revision of the paper. All authors read and approved the final manuscript.

Acknowledgments

We thank the reviewers for their valuable comments and suggestions.

\section{Reference}

Chen, J.D., Xu, C., Cui, L.B., Huang, S., Song, M.L., 2019. Driving factors of CO2 emissions and inequality characteristics in China: A combined decomposition approach. Energy Economics 78, 589-597.

Cui, C., Wang, Z., Cai, B.F., Peng, S., Wang, Y., Xu, C.D., 2021. Evolution-based CO2 emission baseline scenarios of Chinese cities in 2025. Applied Energy 281.

Deng, M.J., Zhong, S.H., Xiang, G.C., 2019. CEs reduction effect of China's final demand structure change from 2013 to 2020: a scenario-based analysis. Carbon Management 10, 387-404.

Ding, S.T., Zhang, M., Song, Y., 2019. Exploring China's CEs peak for different carbon tax scenarios. Energy Policy $129,1245-1252$.

Huang, F., Zhou, D., Wang, Q., Hang, Y., 2019. Decomposition and attribution analysis of the transport sector's carbon dioxide intensity change in China. Transportation Research Part A: Policy and Practice 119, 343-358. 
IEA, 2018. World Energy Outlook 2018. International Energy Agency.

IPCC, 2006. Greenhouse gas inventory: IPCC guidelines for national greenhouse gas inventories. United Kingdom Meteorological Office, England.

Jiang, J.J., Ye, B., Xie, D.J., Tang, J., 2017. Provincial-level CEs drivers and emission reduction strategies in China: Combining multi-layer LMDI decomposition with hierarchical clustering. Journal of Cleaner Production 169, 178-190. Jiang, K.J., He, C.M., Dai, H.C., Liu, J., Xu, X.Y., 2018. Emission scenario analysis for China under the global 1.5 degrees $\mathrm{C}$ target. Carbon Management 9, 481-491.

Li, A.J., Zhang, A.Z., Zhou, Y.X., Yao, X., 2017a. Decomposition analysis of factors affecting carbon dioxide emissions across provinces in China. Journal of Cleaner Production 141, 1428-1444.

Li, H., Zhao, Y.H., Qiao, X.Y., Liu, Y., Cao, Y., Li, Y., Wang, S., Zhang, Z.H., Zhang, Y.F., Weng, J.F., 2017b. Identifying the driving forces of national and regional $\mathrm{CO} 2$ emissions in China: Based on temporal and spatial decomposition analysis models. Energy Economics 68, 522-538.

Lin, B.Q., Liu, W.S., 2017. Scenario Prediction of Energy Consumption and CO2 Emissions in China's Machinery Industry. Sustainability 9.

Liu, B.Q., Shi, J.X., Wang, H., Su, X.L., Zhou, P., 2019a. Driving factors of CEs in China: A joint decomposition approach based on meta-frontier. Applied Energy 256.

Liu, N., Ma, Z., Kang, J., Su, B., 2019b. A multi-region multi-sector decomposition and attribution analysis of aggregate carbon intensity in China from 2000 to 2015. Energy Policy 129, 410-421.

Liu, Q., Zheng, X.Q., Zhao, X.C., Chen, Y., Lugovoy, O., 2018. CEs scenarios of China's power sector: Impact of controlling measures and carbon pricing mechanism. Advances in Climate Change Research 9, 27-33.

Long, X., Sun, M., Cheng, F., Zhang, J., 2017. Convergence analysis of eco-efficiency of China's cement manufacturers through unit root test of panel data. Energy 134, 709-717.

NBSC, 1998-2018a. China Electricity Statistical Yearbook. National Bureau of Statistics of China, Beijing.

NBSC, 1998-2018b. Chinese Energy Statistics Yearbook. National Bureau of Statistics of China, Beijing.

NBSC, 1998-2018c. Chinese Statistics Yearbook. National Bureau of Statistics of China, Beijing.

NDRC, 2016. The 13th Five-Year Plan for Economic and Social Development of the People's Republic of China, p. http://en.ndrc.gov.cn/policyrelease/201612/P020161207645766966662.pdf.

NDRC, 2017. "Thirteenth Five-Year Plan" for the Construction of Water-Saving Society. National Development and Reform Commission.

NDRC, 2021. The 14th Five-Year Plan for Energy Development, in: Commission, N.D.a.R. (Ed.). National Development and Reform Commission.

Niu, D.X., Wang, K.K., Wu, J., Sun, L.J., Liang, Y., Xu, X.M., Yang, X.L., 2020. Can China achieve its 2030 CEs commitment? Scenario analysis based on an improved general regression neural network. Journal of Cleaner Production 243.

OECD, 2019. Long-term baseline projections, no. 103. OECD Economic Outlook: Statistics and Projections. https://doi.org/10.1787/68465614-en.

Qiao, H., Chen, S., Dong, X., Dong, K., 2019. Has China's coal consumption actually reached its peak? National and regional analysis considering cross-sectional dependence and heterogeneity. Energy Economics 84.

Qin, J.C., Tao, H., Zhan, M.J., Munir, Q., Brindha, K., Mu, G.J., 2019. Scenario Analysis of CEs in the Energy Base, Xinjiang Autonomous Region, China. Sustainability 11.

Song, Y., Sun, J.J., Zhang, M., 2021. Research on Evolution in the Center of Gravity and a Contribution Decomposition of Energy-Related CO2 Emissions at the Provincial Level in China. Emerg Mark Financ Tr 57, 684-697.

Sun, Z.R., Liu, Y.D., Yu, Y.N., 2019. China's CEs peak pre-2030: Exploring multi-scenario optimal low-carbon behaviors for China's regions. Journal of Cleaner Production 231, 963-979.

Tang, Z., Bai, S., Shi, C., Liu, L., Li, X., 2018. Tourism-Related CO2 Emission and Its Decoupling Effects in China: A Spatiotemporal Perspective. Advances in Meteorology 2018, 1-9.

UN, 2018. World Population Prospects:2018. United Nation, p. https://population.un.org/wup/Publications/. 
Wang, H., Zhou, P., 2018. Multi-country comparisons of $\mathrm{CO} 2$ emission intensity: The production-theoretical decomposition analysis approach. Energy Economics 74, 310-320.

Wang, J., Yang, H.Z., Lu, Z.B., 2010. Energy Demand Outlook and Scenario Analysis of Carbon Dioxide Emission of China. 2010 the Second China Energy Scientist Forum, Vol 1-3, 1280-1286.

Wang, M., Feng, C., 2017. Decomposition of energy-related CO2 emissions in China: An empirical analysis based on provincial panel data of three sectors. Applied Energy 190, 772-787.

Wang, Q., Li, R.R., Jiang, R., 2016a. Decoupling and Decomposition Analysis of CEs from Industry: A Case Study from China. Sustainability 8.

Wang, Q.W., Chiu, Y.H., Chiu, C.R., 2015. Driving factors behind carbon dioxide emissions in China: A modified production-theoretical decomposition analysis. Energy Economics 51, 252-260.

Wang, S., Fang, C., Wang, Y., 2016b. Spatiotemporal variations of energy-related CO2 emissions in China and its influencing factors: An empirical analysis based on provincial panel data. Renew Sust Energ Rev 55, 505-515.

Wang, S.J., Wang, J.Y., Li, S.J., Fang, C.L., Feng, K.S., 2019. Socioeconomic driving forces and scenario simulation of CO2 emissions for a fast-developing region in China. Journal of Cleaner Production 216, 217-229.

Wang, W.Y., Wang, J., Guo, F., 2018a. Carbon Dioxide (CO2) Emission Reduction Potential in East and South Coastal China: Scenario Analysis Based on STIRPAT. Sustainability 10.

Wang, Y., Zhou, Y., Zhu, L., Zhang, F., Zhang, Y., 2018b. Influencing Factors and Decoupling Elasticity of China's Transportation Carbon Emissions. Energies 11.

Wen, L., Liu, Y.J., 2016. The Peak Value of CEs in the Beijing-Tianjin-Hebei Region Based on the STIRPAT Model and Scenario Design. Polish Journal of Environmental Studies 25, 823-834.

Xiao, H., Sun, K.-J., Bi, H.-M., Xue, J.-J., 2019. Changes in carbon intensity globally and in countries: Attribution and decomposition analysis. Applied Energy 235, 1492-1504.

Xu, S.C., He, Z.X., Long, R.Y., 2014. Factors that influence CEs due to energy consumption in China: Decomposition analysis using LMDI. Applied Energy 127, 182-193.

You, Z.W., Zhao, T., Song, C., Wang, J., 2021. Analyzing China's coal-related CEs from economic growth perspective: Through decoupling and decomposition model. Environmental Science and Pollution Research 28, 3703-3718.

Yu, M., Liu, F.Y., Shu, M.D., Liu, J.P., Chen, C., 2019. Quantitative analysis and scenario prediction of energy consumption CEs in urban agglomerations in China: Case of Beijing-Tianjin-Hebei region. Third International Conference on Energy Engineering and Environmental Protection 227.

Yuan, R., Rodrigues, J.F.D., Tukker, A., Behrens, P., 2018. The impact of the expansion in non-fossil electricity infrastructure on China's carbon emissions. Applied Energy 228, 1994-2008.

Zhang, C., Su, B., Zhou, K.L., Yang, S.L., 2019. Decomposition analysis of China's CO2 emissions (2000-2016) and scenario analysis of its carbon intensity targets in 2020 and 2030. Science of the Total Environment 668, 432-442.

Zhang, M., Bai, C., Zhou, M., 2018. Decomposition analysis for assessing the progress in decoupling relationship between coal consumption and economic growth in China. Resources, Conservation and Recycling 129, 454-462.

Zhang, P.Y., He, J.J., Hong, X., Zhang, W., Qin, C.Z., Pang, B., Li, Y.Y., Liu, Y., 2017. Regional-Level CEs Modelling and Scenario Analysis: A STIRPAT Case Study in Henan Province, China. Sustainability 9.

Zhang, S., Zhao, T., 2019. Identifying major influencing factors of CO2 emissions in China: Regional disparities analysis based on STIRPAT model from 1996 to 2015. Atmospheric Environment 207, 136-147.

Zhang, X., Geng, Y., Shao, S., Dong, H.J., Wu, R., Yao, T.L., Song, J.K., 2020. How to achieve China's CO2 emission reduction targets by provincial efforts? - An analysis based on generalized Divisia index and dynamic scenario simulation. Renew Sust Energ Rev 127.

Zhu, C.Z., Wang, M., Du, W.B., 2020. Prediction on Peak Values of Carbon Dioxide Emissions from the Chinese Transportation Industry Based on the SVR Model and Scenario Analysis. J Adv Transport 2020. 
Figures

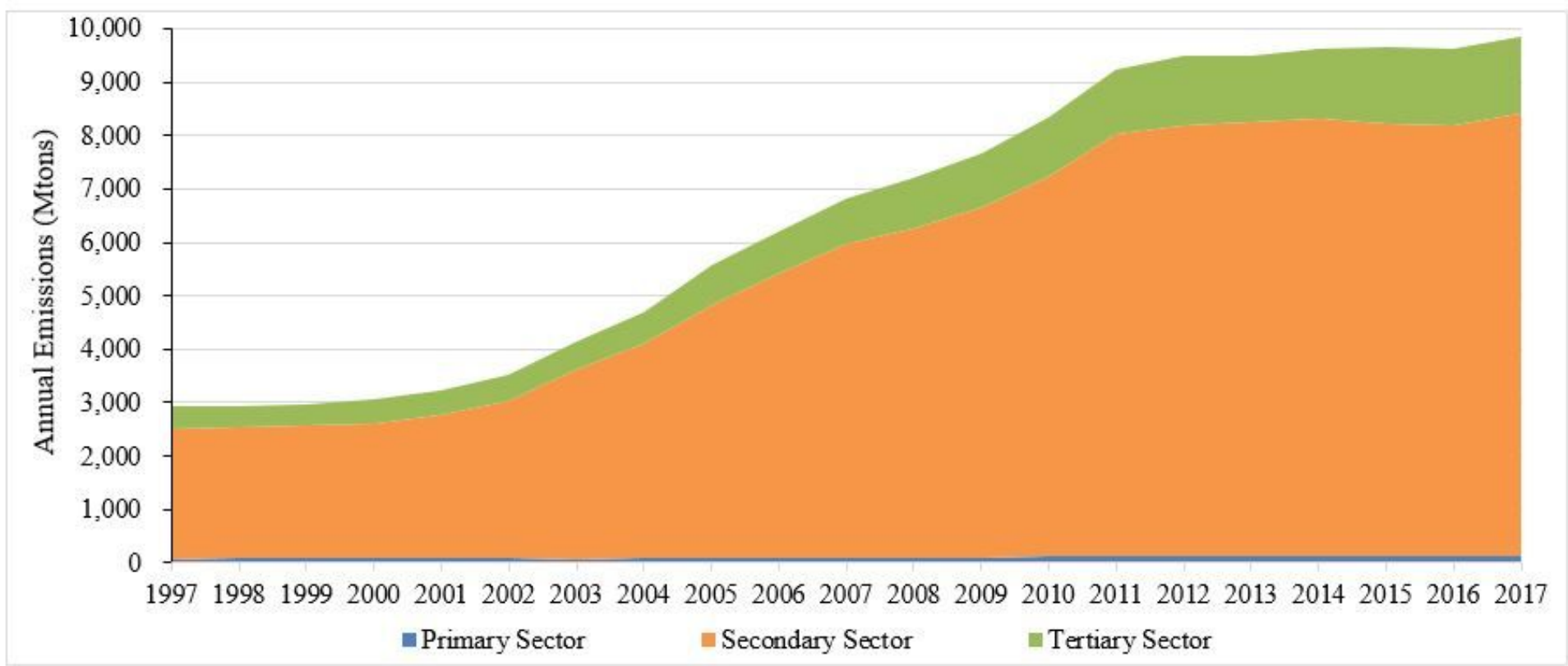

\section{Figure 1}

China's CEs during 1997-2017 


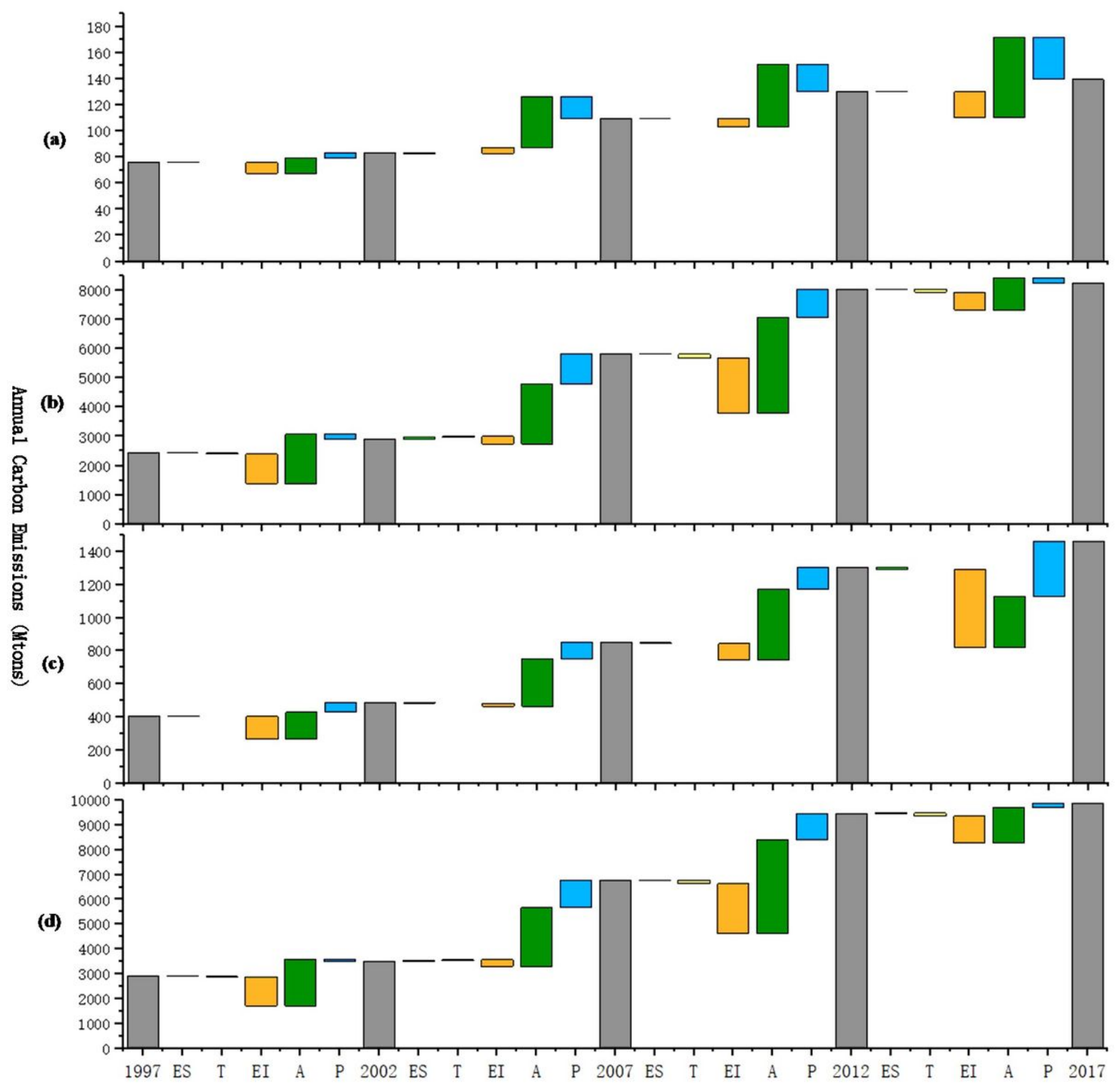

Figure 2

Decomposition result of historical CEs during 1997-2017 (a) Primary Sector; (b) Secondary Sector; (c) Tertiary Sector; (d) National Total 


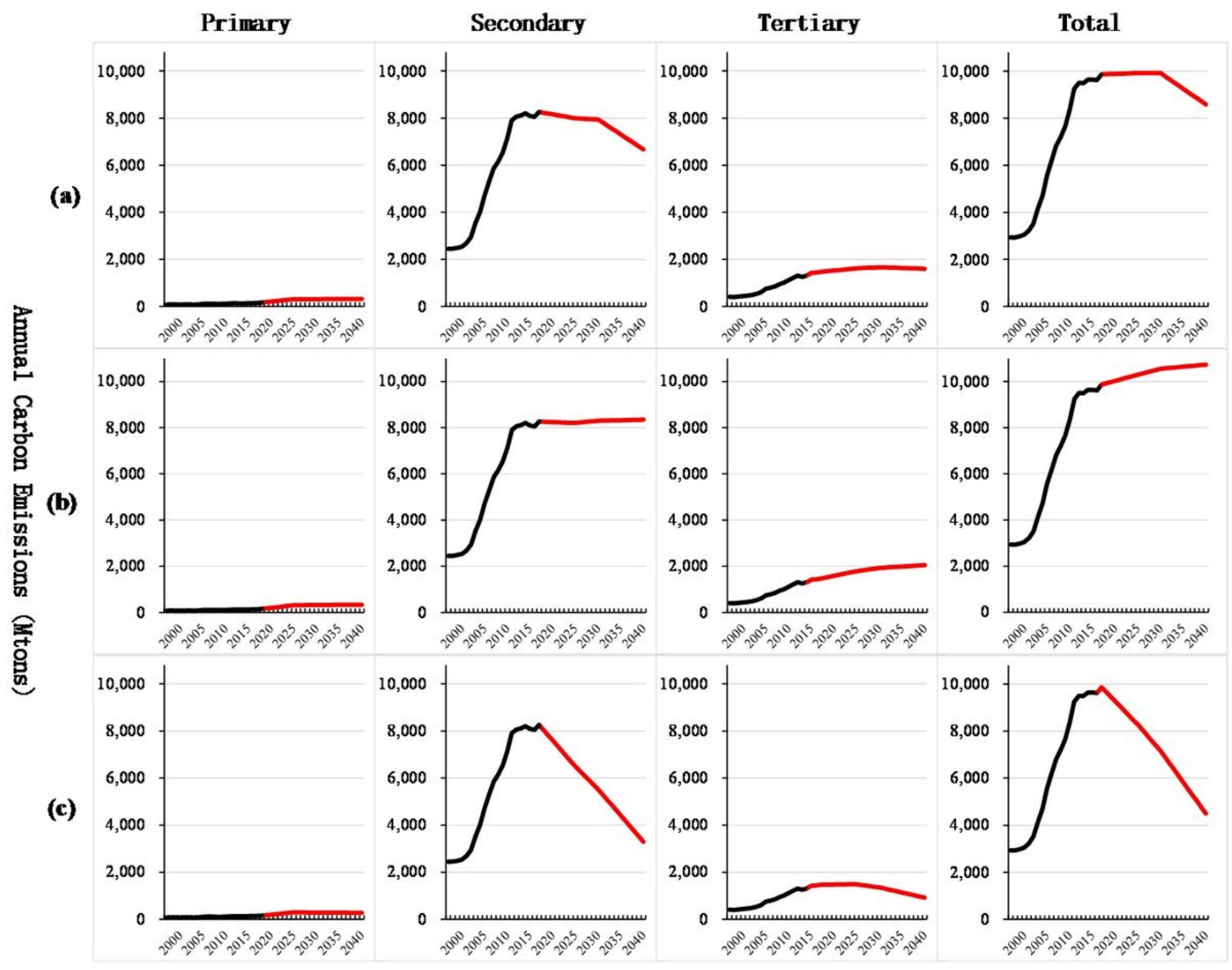

Figure 3

China's CEs during 1997-2040 in different sector. (a) New Policies Scenario; (b) Current Policies 


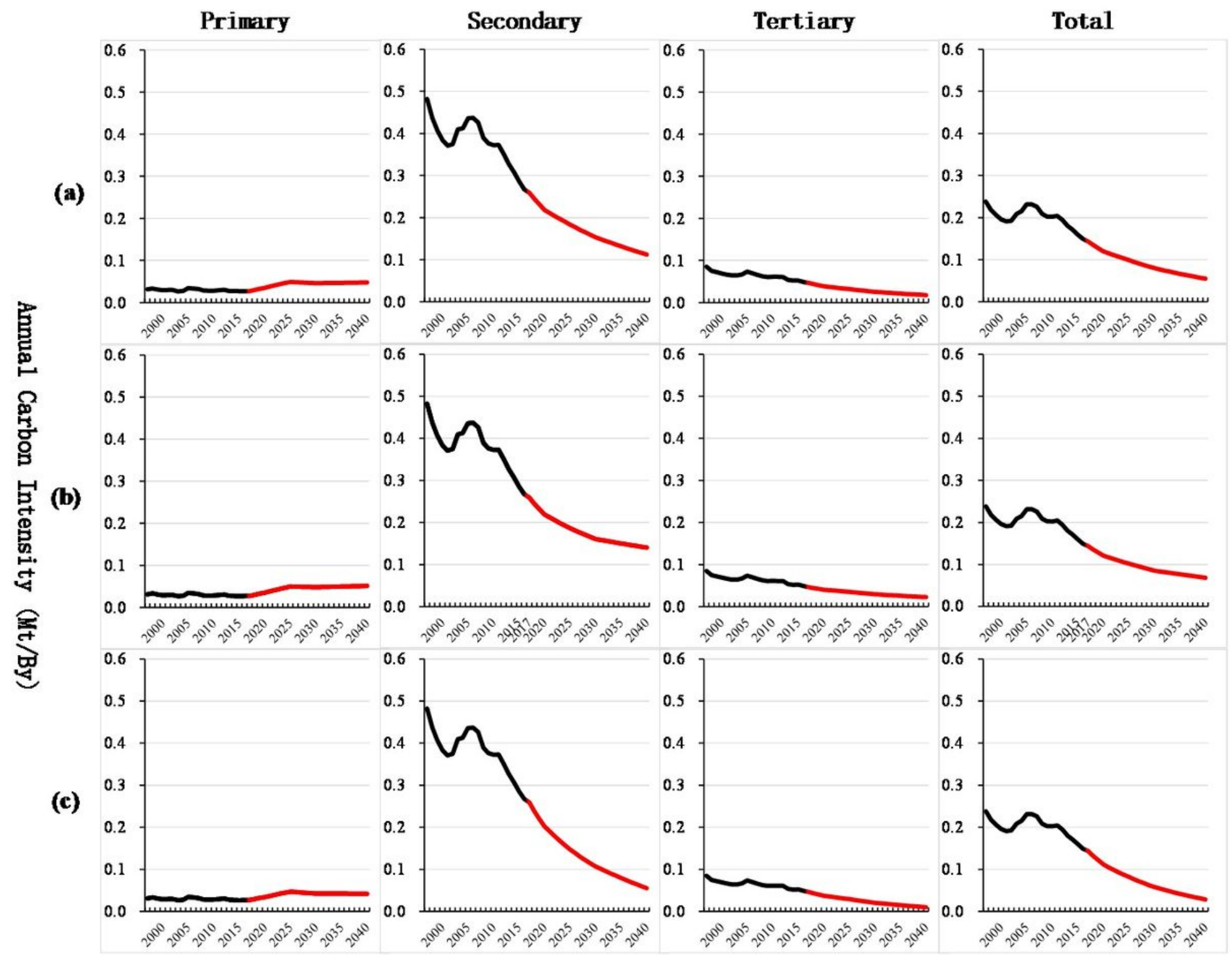

Figure 4

China's Cl during 1997-2040 in different sector. (a) New Policies Scenario; (b) Current Policies Scenario; (c) Sustainable Development Scenario. 


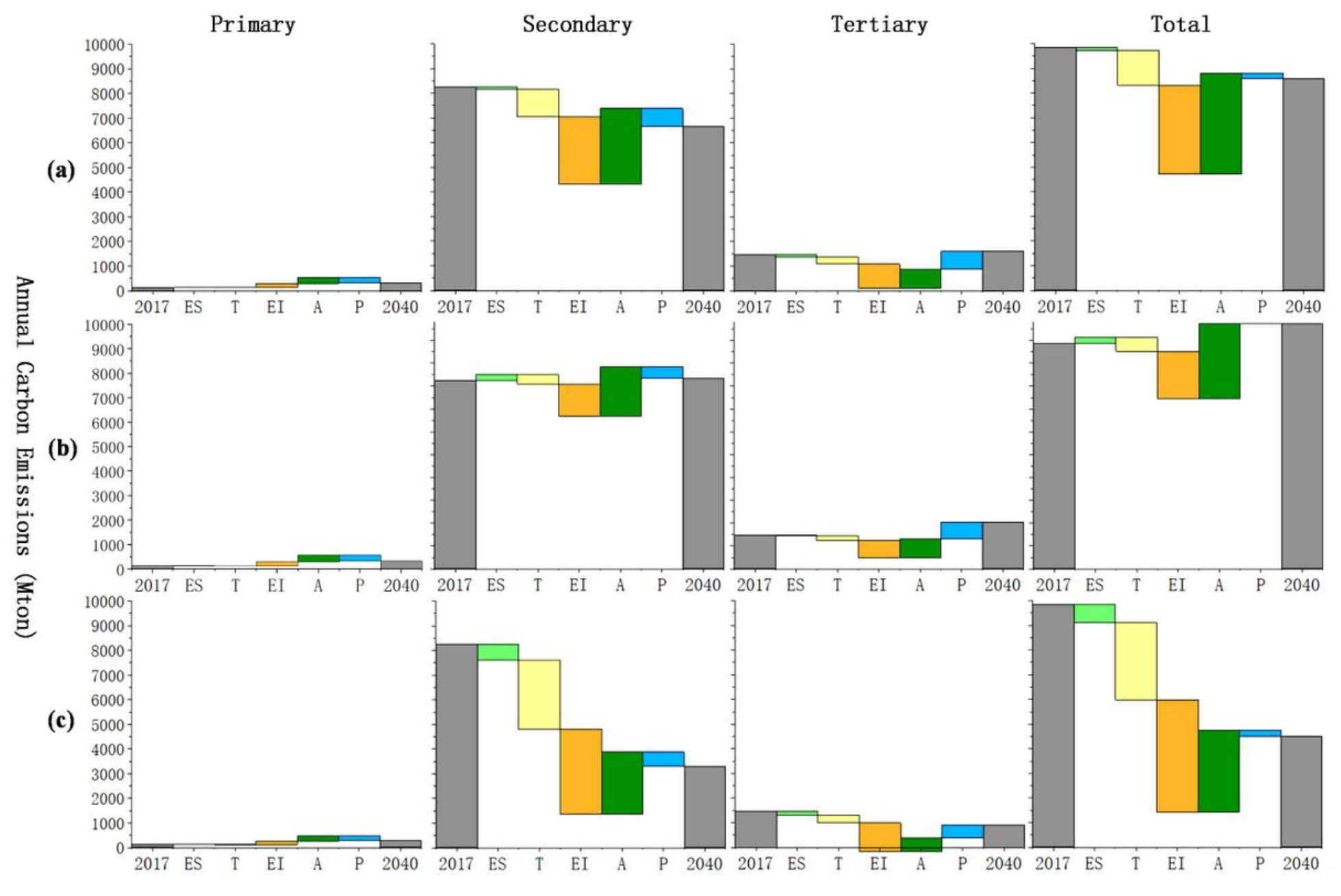

Figure 5

Decomposition result of China's CEs during 1997-2040 in different sector. (a) New Policies Scenario; (b) Current Policies Scenario; (c) Sustainable Development Scenario. 


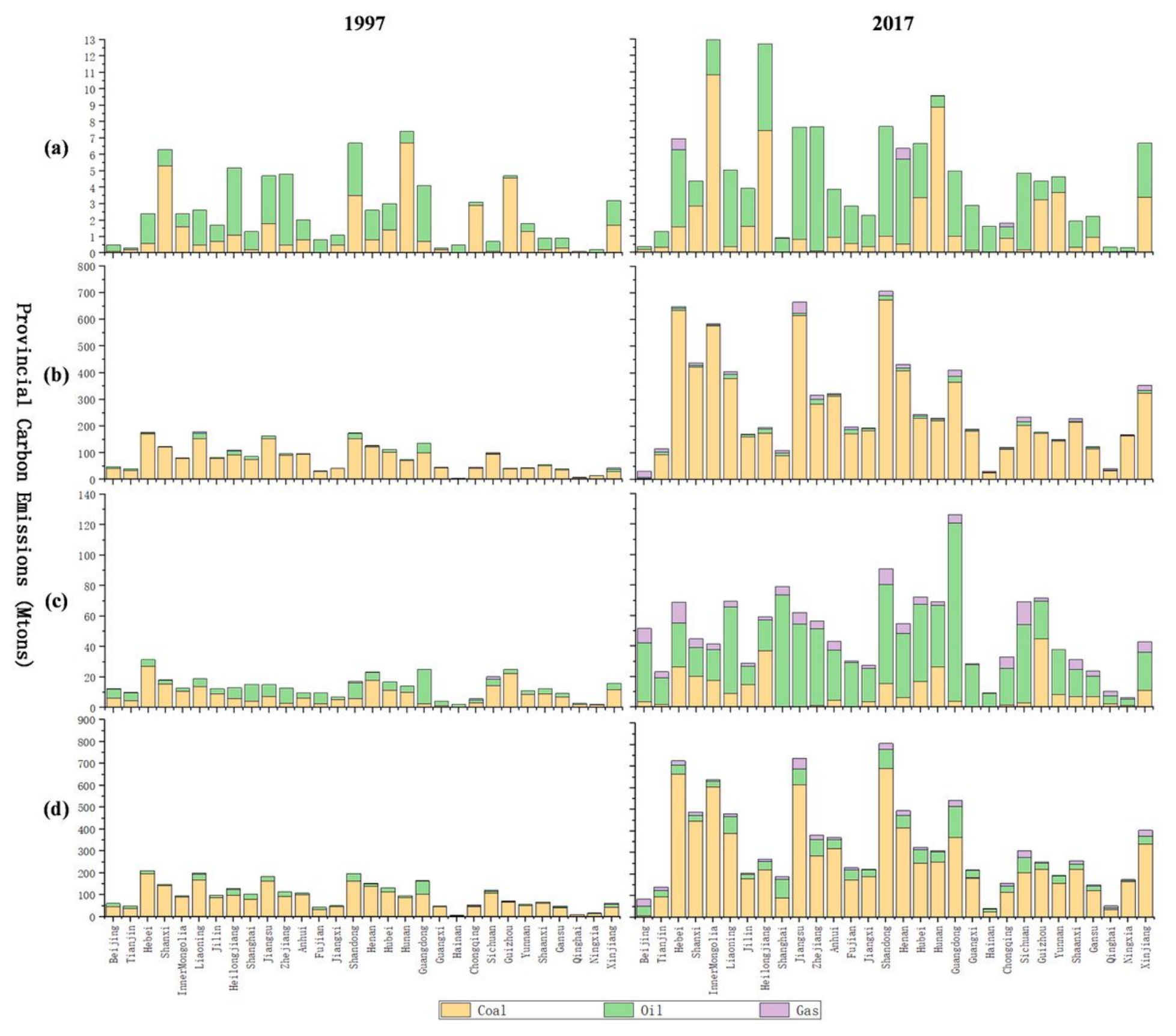

Figure 6

Provincial CEs during 1997-2017 (a) Primary Sector; (b) Secondary Sector; (c) Tertiary Sector; (d) National Total. 


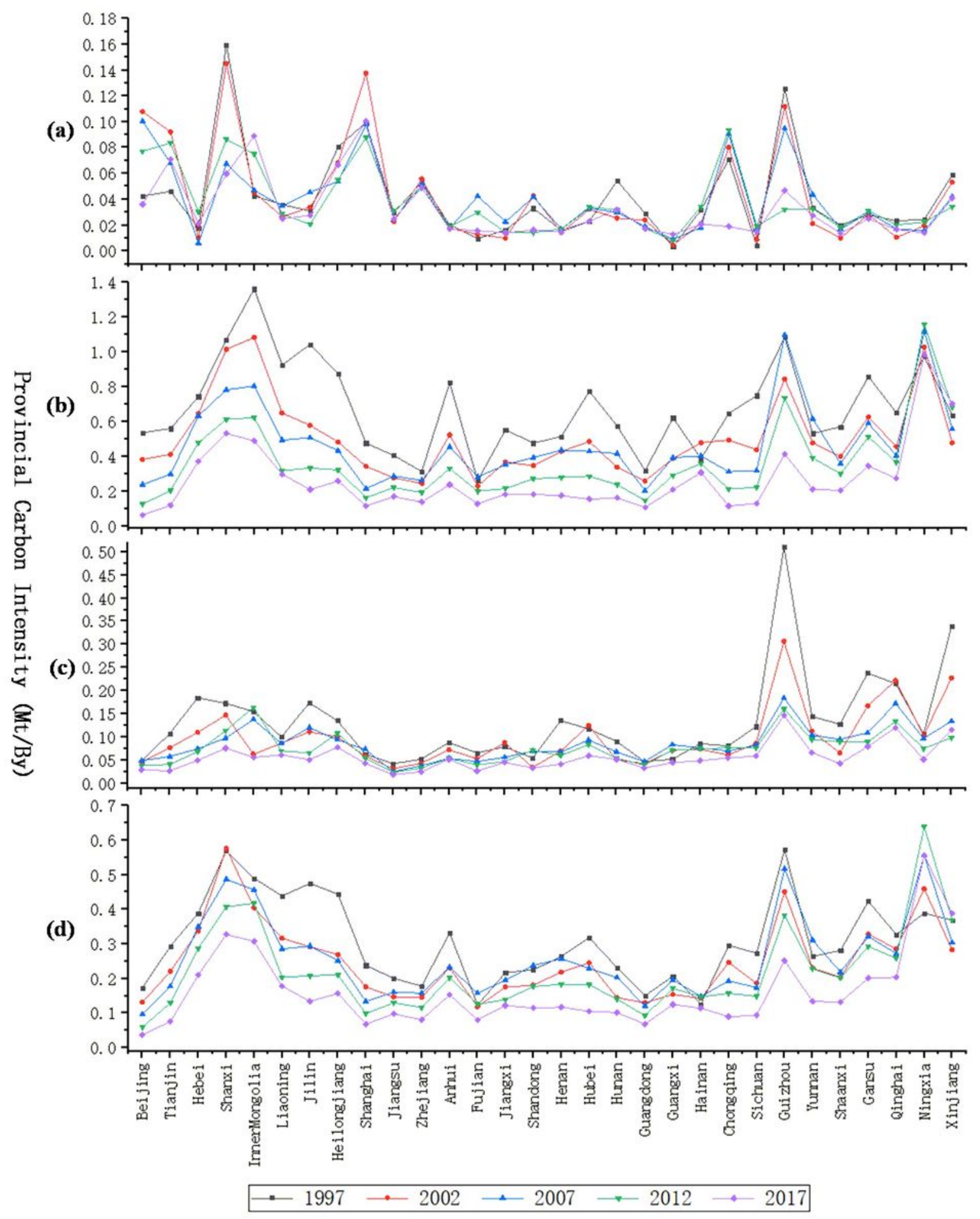

Figure 7

Provincial Cl during 1997-2017 (a) Primary Sector; (b) Secondary Sector; (c) Tertiary Sector; (d) National Total.

\section{Supplementary Files}


This is a list of supplementary files associated with this preprint. Click to download.

- GraphicalAbstract.docx

- 2017emissionsprovincial.xlsx

- 2017energyconsumptionprovincial.xlsx

- 2017nonfossil.xlsx

- 2017populationGDP.xIsx

- Emissionssector20302040.xlsx

- TPEDsector20302040.xIsx 